\title{
The Humanistic and Economic Burden of Alzheimer's Disease
}

Amir Abbas Tahami Monfared • Michael J. Byrnes (D) •

Leigh Ann White · Quanwu Zhang

Received: December 10, 2021 / Accepted: February 3, 2022 / Published online: February 22, 2022

(C) The Author(s) 2022

\section{ABSTRACT}

Alzheimer's disease (AD) is the leading cause of cognitive impairment and dementia in older individuals (aged $\geq 65$ years) throughout the world. As a result of these progressive deficits in cognitive, emotional, and physical function, AD dementia can cause functional disability and loss of independence. To gain a deeper understanding of the recent literature on the burden of $\mathrm{AD}$, including that of mild cognitive impairment (MCI) due to $\mathrm{AD}$, we conducted a comprehensive targeted review of the PubMedindexed literature (2014 to 2021) to examine the humanistic and economic burden of $\mathrm{AD}$ (including MCI) in North America, Europe, and Asia. Our literature review identified a range of factors associated with quality of life (QoL): some factors were positively associated with QoL, including caregiver relationship, religiosity, social engagement, and ability to engage in activities of daily living (ADL), whereas other factors such as neuropsychiatric symptoms were

A. A. Tahami Monfared $(\bowtie) \cdot$ Q. Zhang

Eisai, 200 Metro Blvd, Nutley, NJ 07110, USA

e-mail: amir_tahami@eisai.com

\section{A. A. Tahami Monfared}

McGill University, Epidemiology, Biostatistics and

Occupational Health, Montreal, QC, Canada

M. J. Byrnes - Leigh. A. White

Evidera, Waltham, MA, USA associated with poorer QoL. While patient- and proxy-rated QoL are highly correlated in patients with early AD dementia, proxy-rated QoL declines more substantially as severity worsens. The maintenance of self-reported QoL in patients with more severe $\mathrm{AD}$ dementia may be due to lack of awareness or to adaptation to circumstances. Compared to persons with normal cognition, $\mathrm{MCI}$ is associated with a greater cost burden, and individuals with MCI exhibit worse QoL. Key drivers of the societal economic burden of AD include disease severity, dependence level, institutionalization, and comorbidity burden. Evaluation of the impact of a hypothetical disease-modifying treatment delaying the progression from $\mathrm{MCI}$ to $\mathrm{AD}$ has suggested that such a treatment may result in cost savings.

Keywords: Alzheimer's disease; Economic burden; Humanistic burden; Informal care costs; Mild cognitive impairment 


\section{Key Summary Points}

As Alzheimer's disease (AD) is the leading cause of age-related dementia worldwide, and several novel therapies for this disease are in advanced stages of development, a synthesis of the published evidence on its humanistic and economic burden will be useful in understanding the potential benefits of these treatments.

Our review of the literature demonstrated the considerable humanistic burden of AD dementia, highlighted common instruments used to assess quality of life (QoL) in this population, identified key factors that affect QoL in patients with $\mathrm{AD}$ dementia, and explored the differences between patient- and caregiver-rated assessments of QoL.

Our review of the literature on the economic burden of AD identified informal care costs as a key driver of the economic burden of $\mathrm{AD}$.

Literature on the humanistic and economic burden of mild cognitive impairment (MCI) due to AD suggested that while this condition is burdensome, therapies that could delay the progression of MCI to AD may improve patient QoL and lead to cost savings.

\section{INTRODUCTION}

Alzheimer's disease (AD) is the leading cause of cognitive impairment and dementia in older individuals (aged $\geq 65$ years) throughout the world [1]. As such, $\mathrm{AD}$ is one of the leading causes of morbidity and mortality globally, with substantial economic costs and burden to health service provision.

$\mathrm{AD}$ follows a prolonged, progressive disease course that begins with pathophysiological changes in the brains of affected individuals years before any clinical manifestations are observed [2]. These pathophysiological changes include the accumulation of toxic species of amyloid- $\beta(A \beta)$ and the development of neurofibrillary tangles of hyperphosphorylated tau protein [3]. Individuals harboring such changes may be asymptomatic or may exhibit clinical manifestations that may vary from mild cognitive impairment (MCI) to the severe and debilitating loss of memory and cognitive function characteristic of AD dementia [2]. In addition to the cognitive effects of the disease, patients with $\mathrm{AD}$ dementia may also experience increased anxiety and depression in the early stages, and neuropsychiatric symptoms such as confusion, aggression/agitation, and delusion/ hallucination in later stages.

As a result of these progressive deficits in cognitive, emotional, and physical function, $\mathrm{AD}$ dementia can cause functional disability and loss of independence. In the early stages, the main symptom of $\mathrm{AD}$ is memory lapses, and patients may experience increased anxiety or depression [1-3]. As the disease progresses, there are additional signs of neuropsychiatric symptoms such as periods of confusion, disorientation, mood change, aggression/agitation, and eventually delusion/hallucination in later stages.

As $\mathrm{AD}$ is a progressive debilitating disease, its financial burden is staggering [4-7]. Patients at advanced stages of AD dementia incur a significant cost of care, including both formal medical and non-medical care (direct costs) as well as informal caregiving costs. Indirect costs due to reduced productivity of patients and caregivers are also substantial, as well as intangible costs due to pain and suffering of patients and their families.

To gain a deeper understanding of the recent literature on the burden of $\mathrm{AD}$, including that of MCI and dementia, we conducted a literature review of the epidemiological, clinical, humanistic, and economic burden of $\mathrm{AD}$, with a focus on recent English-language literature published in North America, Europe, and Asia. 


\section{METHODS}

A comprehensive review was conducted of the recent literature on the humanistic and economic burden of AD in North America, Europe, and Asia. Our primary literature search covered the PubMed-indexed literature published between 2014 and January 2021 and included search terms related to $\mathrm{AD}$ (including $\mathrm{MCI}$ ) and to humanistic and economic burden (e.g., "quality of life," "utility," "utilities," "hrqol," "qol," "cost," "costs," "economic," "expenditure," "productivity," "resource use," "resource utilization," "absenteeism," "presenteeism," "work disability") as well as relevant Medical Subject Heading (MeSH) terms for AD/MCI and humanistic/economic burden. Supplemental searches of indexed and non-indexed literature were also conducted.

Articles identified in the literature search were considered for inclusion if they reported relevant outcomes (i.e., pertaining to the humanistic or economic outcomes of AD) either globally or in the United States (USA), France, Germany, Italy, Spain, the United Kingdom (UK), China, or Japan. The year 2014 was selected as a cutoff date in an effort to focus our review on studies published after the publication of the 2011 National Institute on Aging-Alzheimer's Association (NIA-AA) guidelines, which defined three phases of AD: preclinical AD (early pathological changes in the brains of cognitively normal individuals), MCI (symptomatic predementia), and dementia [8-10]; additionally, we did not want to look further back than 2014 for studies of economic data, as such data may lose value over time due to changes in healthcare policy and practice patterns as well as cost inflation.

Articles reporting on patients with AD were prioritized, whereas articles reporting on related populations (e.g., patients with dementia, AD and related dementia [ADRD], or $\mathrm{AD}$ and other dementia [ADOD]) were not prioritized unless they reported specific information on patients with AD. Where many articles on a specific topic were identified, those publishing unique information were prioritized for inclusion. Additional priorities included more recently published articles and, where relevant, studies of larger patient populations and studies reporting on longer periods of follow-up. In total, 93 articles were selected for inclusion in this literature review.

The focus of the section on humanistic outcomes was on identifying AD- or dementiaspecific instruments, discrepancies between patient- and proxy-reported measures, factors that affect quality of life (QoL) in patients with $\mathrm{AD}$ including disease stage and severity, and assessment of activities of daily living (ADL) and utilities in patients with AD. As the use of disease-specific instruments for assessment of ADL and utility was less common than for assessment of QoL, some reporting of general instruments was included in those sections.

The focus in the section on economic burden is on the total societal cost burden of AD (including both direct and indirect costs) and key cost drivers, and resource use associated with $\mathrm{AD}$. As the economic burden section included studies that reported on costs over a wide range of time periods (e.g., per day, per month, per quarter, per year), all costs were expressed as monthly costs. This article is based on previously conducted studies and does not contain any new studies with human participants or animals performed by any of the authors.

\section{RESULTS}

\section{Humanistic Burden of AD}

For patients with dementia, cognition, ADLs, social interaction, and psychological factors interact in a complex fashion to affect QoL $[11,12]$. Measuring QoL is complicated because of the many factors that can affect QoL, as well as the difficulty in obtaining accurate self-reported information in this population.

\section{Common Instruments Used to Assess QoL in Patients with AD}

Numerous instruments, both dementia-specific and general, have been used to evaluate QoL in individuals with $\mathrm{AD}$. A systematic literature review (SLR) and meta-analysis by Martyr et al. comprising 205 studies evaluating QoL in 
Table 1 Dementia-specific quality of life and activities of daily living instruments $[13,14]$

\begin{tabular}{|c|c|}
\hline Quality of life (QoL) instruments & Activities of daily living (ADL) instruments \\
\hline Activity and Affect Indicators of QOL (AAIQoL) & - Alzheimer's Disease Cooperative Study-Activities of Daily \\
\hline Alzheimer's Disease Related Quality of Life (ADRQL) & Living (ADCS-ADL) \\
\hline $\begin{array}{l}\text { Bath Assessment of Subjective Quality of Life in } \\
\text { Dementia (BASQID) }\end{array}$ & $\begin{array}{l}\text { Alzheimer's Disease Functional Assessment and Change Scale } \\
\text { (ADFACS) }\end{array}$ \\
\hline Community Dementia Quality of Life Profile & Bristol Activities of Daily Living Scale (BADLS) \\
\hline (CDQLP) & Dependence Scale (DS) \\
\hline Cornell-Brown Scale for Quality of Life in Dementia & Disability Assessment for Dementia (DAD) \\
\hline (CBSQLD) & Functional Activities Questionnaire (FAQ) \\
\hline Dementia Quality of Life Instrument (DQoL) & Interview for Deterioration in Daily Living Activities in \\
\hline Dementia Quality of Life Questionnaire (DEMQOL) & Dementia (IDDD) \\
\hline \multicolumn{2}{|l|}{ Observable Displays of Affect Scale (ODAS) } \\
\hline \multicolumn{2}{|l|}{ Observed Emotion Rating Scale (OERS) } \\
\hline \multicolumn{2}{|l|}{ Pleasant Events Schedule-Alzheimer's disease (PES-AD) } \\
\hline \multicolumn{2}{|l|}{ Quality of Life in Alzheimer's Disease (QoL-AD) } \\
\hline \multicolumn{2}{|l|}{ QUAlity of LIfe in DEMentia (QUALIDEM) } \\
\hline \multicolumn{2}{|l|}{$\begin{array}{l}\text { Quality of Life in Late-Stage Dementia Scale } \\
\text { (QUALID) }\end{array}$} \\
\hline Quality of Life Questionnaire for Dementia (QLQD) & \\
\hline
\end{tabular}

patients with dementia identified 14 dementiaspecific instruments (Table 1), as well as even more general QoL instruments, that had been used to evaluate these patients [13]. The Quality of Life in Alzheimer's Disease (QoL-AD) was the most commonly used instrument in studies in which the rating was performed by the patient or caregiver/healthcare professional (informantrated), while the Dementia Quality of Life Questionnaire (DEMQOL) was most commonly used in proxy-rated studies (in which a caregiver or healthcare professional chooses the rating the patient would theoretically make) [13]. In contrast, a consensus conference and SLR of pharmacological intervention trials for dementia by Webster et al. identified only three scales: the general European Quality of Life-5 Dimensions (EQ-5D) scale, the DEMQOL, and the QoLAD [14]. This same SLR identified 11 instruments that were used to evaluate ADLs, of which seven were specific to dementia patients (Table 1) [14].

Disease-specific instruments for measuring QoL in patients with dementia have been recommended over general instruments [14]. For example, it has been suggested that the EQ-5D, while widely used for a variety of disease states, may be less useful in patients with dementia because it focuses on generic health status and may not be sensitive enough to distinguish caregiver burden for dementia patients $[15,16]$. In contrast, a study evaluating the QoL-AD in elderly medical patients (but not diagnosed with dementia) found that QoL-AD results were not correlated with medical comorbidities, which might allow patients and caregivers to focus on mental health in their assessments [17]. As illustrative of the different results that can be found when comparing various instruments, in a Norwegian study of people in nursing homes, the QoL-AD and EQ-5D showed 
that those without dementia had higher scores, but QoL assessed by a patient- and staff-rated visual analogue scale (VAS) showed the reverse, results that the investigators felt were based on the differing factors measured in each scale that had implications for patients with dementia [15].

\section{Factors Associated with QoL in Patients with Dementia}

Given the many factors that can contribute to QoL, a number of researchers have investigated which are most important for dementia patients. In the meta-analysis noted above by Martyr et al., the most important factors for better QoL were the relationship with the caregiver, religious beliefs or spirituality, and greater social engagement; factors such as functional ability, self-rated health and awareness, care in a special dementia unit or living in a community with a spouse, and white race were next in importance; and demographic factors were found to have little impact on QoL [13]. The most important factor associated with poor QoL was neuropsychiatric symptoms, including depression [13]. Poorer QoL also had a small association with more severe dementia, other medical conditions, pain and anxiety, unmet needs, and living alone [13].

Several studies have found that depression/mood/psychiatric comorbidity is a key factor in patients with a clinical diagnosis of AD dementia based on the Diagnostic and Statistical Manual of Mental Disorders, 4th Edition (DSM-IV) and/or the 1984 National Institute of Neurological and Communicative Disorders and Stroke (NINCDS) and the Alzheimer's Disease and Related Disorders Association (ADRDA) guidelines [12, 18-28]. For example, in a French study of 123 patients with mild to moderate AD, when measured by the QoL-AD, depression $(p<0.001)$ was significantly associated with poorer QoL for the overall score in multivariate analysis; this association was significant for both self-report $(p<0.05)$ and caregiver report $(p<0.001)$ [21]. Similarly, in a Spanish study of 92 patients with $\mathrm{AD}$, depression had a more important effect on QoL, measured by the QoL$\mathrm{AD}$, than did the loss of functional abilities [20]. Several studies that developed regression models evaluating the various factors that affect QoL found that psychiatric comorbidity and/or depression were key predictors of lower QoL, particularly for caregiver-rated QoL [25-28].

Several studies have examined the association between ADL scales and QoL in patients with dementia $[22,26,28]$. In the population of French patients noted above, data from the Dementia Quality of Life (DQoL) scale were evaluated in concert with data from two general ADL scales using a multivariate analysis [22]. The study found that patients who were able to move about their homes due to maintained motor function $(p=0.02)$ or who could still perform ADLs such as using the telephone $(p=0.05)$, as well as those with disinhibition $(p=0.04)$, had significantly higher scores on the self-esteem domain of the DQoL, and those who had home help $(p=0.0002)$ or disinhibition $(p=0.003)$ had better scores for the negative affect domain [22]. Illustrating the complex nature of QoL, home delivery of meals had a negative effect on some DQoL domains and a positive effect on others; the authors theorized that while home meal delivery might emphasize the patient's limitations, it also might be a source of social interaction [22]. Retention of functional abilities can also have a complex effect: the ability to get dressed without assistance was significantly associated with lower QoL in the negative affect domain of the DQoL $(p=0.0007)$ [22]. While this may reflect the complexity of assessing QoL in people with dementia, the study authors suggested that this observation might be due to difficulties patients experienced while getting dressed, or a lack of desire to get dressed (commonly seen in patients as AD advances) [22]. A cross-sectional survey of patients with $\mathrm{AD}(n=98)$ who lived at home found that patient-rated QoL-AD scores were correlated with impairment of IADL $(p=0.02)$ and $\operatorname{ADL}(p=0.012)$, as were caregiver-rated QoL-AD scores (IADL, $p<0.001$; ADL, $p=0.023$ ) [25]. Another cross-sectional study conducted in German patients with AD $(n=100)$ observed a medium inverse correlation between patient-rated QoL and ADL $(r=-0.34 ; p<0.01)$ and a strong inverse correlation between proxy-rated QoL and ADL $(r=-0.51 ; p<0.01)$ [28]. A larger study 
( $n=264$ patients with AD in Brazil) reported similar findings, observing that functionality as assessed by the Pfeffer Functional Activities Questionnaire was associated with both patientrated and proxy-rated QoL-AD scores [26].

Two studies examined the association between engagement in activities and QoL in patients with dementia [23, 29]. One study investigating the effect of daily activities on QoL was conducted in 115 patients with dementia living in Dutch nursing homes [23]. After QoL was evaluated with the QoL-AD by the staff, patients were divided into "high QoL" and "low QoL" groups based on the median QoL-AD value, and then the types of activities, engagement in activities, social interaction, physical effort, mood, and agitation were monitored [23]. It was found that patients in the high QoL group spent significantly more time in active, expressive, and social activities and less time in passive/purposeless activities than did patients in the low QoL group $(p<0.001$ for both), and were also more clearly engaged in these activities $(p<0.001)$ [23]. Regression analysis showed that social interaction and better mood were associated with better QoL [23]. Of note, the causality of this interaction is unclear; available data do not clarify whether increased social participation is a cause or an effect of higher QoL [23]. Patients in the higher QoL group had significantly higher cognition $(p=0.003)$ [23]. In a study of 1144 patients with dementia living in Dutch nursing homes that evaluated the effect of time spent in activities on QoL, it was found that medium and high activity involvement was correlated with better scores on the QUAlity of LIfe in DEMentia (QUALIDEM) domains of positive affect, restless tense behavior, social relations, and having something to do (independent of help from others), and that high activity involvement was correlated with better scores for the care relationship domain [29]. High activity involvement was also associated with lower scores on positive self-image; the investigators theorized that this could occur because these patients were more likely to be confronted with their limitations [29].

\section{Patient- and Caregiver-Rated QoL}

The ability of patients with dementia to describe their QoL can be limited and/or unreliable, making rating by informants and proxies important [14]. For this reason, the consensus conference/SLR by Webster et al. recommended use of the DEMQOL because it includes both self-rating and proxy-rating components [14]. However, regardless of the instrument that has been used, numerous studies have reported a discrepancy between patient-reported and informant/proxy-reported QoL for patients with dementia, with patients reporting better QoL than their informants/proxies $[12,13,17,25,28,30-35]$. Of note, intermediate to strong correlations have been shown between patient- and proxy-rated QoL assessments $[12,17,28]$. The gap between patientrated and proxy-rated QoL increases as disease severity increases, which may relate to lack of awareness of more severely affected patients $[28,31]$

One of the suggested reasons for this discrepancy is lack of awareness on the part of the patients. This lack of awareness can result in more positive self-reports of QoL and in stable self-reports of QoL over time, while caregivers report a decline [11]. Indeed, a regression analysis found that impaired patient awareness was a predictor of lower caregiverrated QoL but of higher patient-rated QoL [26]. For example, in a study that followed 236 Finnish patients with very mild/mild clinically diagnosed $\mathrm{AD}$ for 5 years, patient-rated QoL (on the QoL-AD) remained stable over the 5 years, even as neuropsychiatric symptoms increased [31]. QoL rated by their caregivers decreased significantly over this period $(p \leq 0.001)$, and was correlated with the presence of neuropsychiatric symptoms at both baseline and 5 years [31]. The investigators noted that the increasing lack of insight of the patients as dementia progressed was a factor in their stable self-reported QoL [31]. Similarly, in a study of Brazilian patients with clinically diagnosed $\mathrm{AD}$, at both baseline and 12 months, caregivers rated patient QoL significantly lower than did the patients [33]. Regression analysis showed that the main factor leading to the discrepancy was impaired awareness by the patients [33]. In 
addition, it has been suggested that lack of awareness in patients with dementia is independent of cognitive level, and that the key ways patients display lack of awareness is in not recognizing decreased QoL or decreased functional abilities [36]. In a US study evaluating the effect of being aware of their diagnosis in patients with clinically diagnosed MCI (63\% aware) or mild AD dementia (34\% aware), patients who were unaware of their diagnosis reported significantly better values on the QoL$\mathrm{AD}$ and DEMQOL than patients who were aware in terms of daily life satisfaction, difficulty due to health in daily life, well-being, cognitive functioning, social relationships, activities, and self-concept $(p<0.001)$, and better QoL on the EQ-5D $(p \leq 0.002)$ even though cognitive functioning and memory impairment did not differ significantly between groups [37]. However, in a Dutch study of patients with youngonset dementia (clinically diagnosed $\mathrm{AD}$ or frontotemporal dementia [FTD]), worse QoL was associated with lower disease awareness [24].

Other potential reasons for the discrepancy between self- and informant-reported QoL for patients with dementia include the types of symptoms shown by the patient (e.g., psychiatric/behavioral symptoms) and their degree of dependence, as well as caregiver factors, such as caregiver burden [30, 32, 34, 35]. For example, regression analysis in a study of Italian patients with clinically diagnosed $\mathrm{AD}$ showed that key factors for the higher self-rated QoL values were depression in patients and caregivers, patient ability to perform ADLs, patient psychiatric/ behavioral symptoms, and caregiver burden [30]. In a UK study of 488 people with mild or moderate dementia, better self-reported QoL was associated with higher self-rated health and lower dementia severity, while caregivers reported better QoL for patients who were younger and had less depression and more ADL independence, and when the caregiver lived with the patient [32]. Higher levels of caregiver stress were associated with poorer caregiverrated patient QoL [32]. Caregiver burden was also reported as an important factor for lower caregiver-reported patient QoL in a study evaluating 110 patients with clinically diagnosed young-onset or late-onset AD [35]. While selfreported and caregiver-reported QoL-AD results did not differ according to whether the patient had young-onset or late-onset AD dementia, caregiver-reported QoL was significantly worse than patient-reported QoL for both groups (young-onset, $p<0.001$; late-onset, $p=0.002$ ) [35]. Regression analysis revealed that caregiver burden was an important factor in caregiver perspective for both groups [35]. A recent regression analysis based on 98 patients with clinically diagnosed $\mathrm{AD}$ dementia found that Neuropsychiatric Inventory (NPI), NPI-distress, and Mini-Mental State Examination (MMSE) scores were associated with proxy-rated QoL, whereas ADL, IADL, and caregiver education were associated with both patient- and proxyrated QoL [25].

A more complex picture was described in a study of dementia patients living in the community versus those living in nursing homes [34]. The patients consistently scored their QoL on the QoL-AD higher than did their caregivers, regardless of their living situation [34]. However, caregivers reported higher QoL for patients living in the community, while patients living in the community self-reported lower QoL than patients living in nursing homes, leading to less discrepancy between self-report and proxy report of QoL for community-dwelling patients [34]. The investigators noted that patients in nursing homes were more dependent and had more behavioral issues, leading to worse caregiver QoL rating, while patients living in the community may have had less opportunities for specialized activities, leading to lower QoL selfrating [34].

Impact of AD Severity and Progression on QoL MCI is associated with lower QoL, increased psychiatric burden (e.g., depression), and reduced social activity [38]. An analysis of individuals with clinically diagnosed MCI $(n=204)$ in China found that depressive symptoms $(p<0.001)$, poor sleep quality $(p=0.004)$, and old age $(p=0.024)$ were predictors of lower QoL (as assessed by the QoLAD) [39]. A larger study that included individuals with normal cognition $(n=99)$, MCI $(n=92)$, and probable AD $(n=68)$ found that 
those with MCI had lower QoL (as assessed by the DEM-QOL), greater depression and subjective stress, and more difficulty with IADLs (all $p<0.05$ ) [40]. Adverse impact on QoL was also seen in individuals with subjective cognitive impairment even without a diagnosis of MCI [41]. In an aging population $(n=1387)$ of whom $50.6 \%$ had subjective cognitive decline (SCD; i.e., performed normally on cognitive tests despite reporting some subjective decline), individuals with SCD had significantly reduced QoL as assessed with a general instrument (the EQ-VAS; $p<0.001$ ) [41]. A recent cross-sectional analysis highlighted that sleep quality (as assessed by the Pittsburgh Sleep Quality Index) was worse in patients with MCI $(n=67)$ and AD dementia $(n=17)$ diagnosed according to 2011 NIA-AA guidelines compared with individuals with normal cognition $(n=46)$ or SCD $(n=91$, including $n=53$ with no memory concerns and $n=38$ with memory concerns) [42]. The difference in sleep quality was significant across the five groups $(p<0.001)$ [42]. Among patients with MCI, poor sleep quality was a predictor of cognitive impairment (odds ratio [OR] 11.0, 95\% confidence interval [CI] 4.5 to 26.98 ) [42]. Among all patient categories, including those with MCI, poor sleep quality was associated with worse 36-Item Short Form Health Survey (SF-36) QoL [42].

A number of studies have reported that selfreported QoL does not decline as clinically diagnosed $\mathrm{AD}$ dementia progresses and that patients with mild, moderate, or severe dementia show little difference in self-reported QoL, although informant-reported QoL shows differences [12, 13, 28, 43-45]. Lack of awareness may be an explanation for the positive selfreports in patients with severe $\mathrm{AD}$ and the unchanged self-reported QoL in patients whose $\mathrm{AD}$ has progressed [43]. It has also been suggested that as $\mathrm{AD}$ progresses, patients may adapt to their limitations and adjust their expectations [43].

In the meta-analysis by Martyr et al., more severe dementia had a small association with poorer QoL, but when the analysis included only long-term studies $(n=20)$, the association of worse QoL with more advanced dementia was not significant [13]. In a study of 525
Spanish patients with clinically diagnosed AD in residential care homes, there was no significant difference in self-rated QoL between patients with mild/moderate or severe dementia, while proxies rated QoL significantly lower in patients with severe dementia $(p<0.001)$ [12]. Similarly, in results from the Spanish component of the GERAS II study, an observational study of patients with clinically diagnosed AD dementia residing in the community, QoL decreased significantly with increasing severity of $\mathrm{AD}$ according to proxy EQ-5D results [44].

A few studies do show self-rated QoL differing by dementia severity. For example, baseline findings from the GERAS-US study showed that patients with clinically diagnosed mild AD had worse self-reported QoL on the Bath Assessment of Subjective Quality of Life in Dementia (BASQID, comprising total score, life satisfaction, feelings of positive QoL; all $p<0.001$ ) compared to patients with MCI [46]. An analysis of patient- and proxy-rated QoL in patient-caregiver dyads $(n=100)$ found that both measures declined with increasing dementia severity, but the decline was more pronounced in proxyrated QoL than in patient-rated QoL [28].

As $\mathrm{AD}$ progresses, patients become more dependent on caregivers, and some studies have evaluated how increasing dependence could affect QoL. For example, in the French component of the GERAS [Geriatric Education and Research in Aging Sciences] study, over 18 months, increasing dependence was significantly associated $(p<0.05)$ with worse QoL as measured by proxy using the EQ-5D [47]. However, different results were found in the UK DADE (Dependence in Alzheimer's Disease) study, in which 145 people with clinically diagnosed mild, moderate, or severe $\mathrm{AD}$ dementia were evaluated at baseline and 18 months [43]. Over 18 months, there was a significant increase in the dependence of the patients, as well as significant reductions in cognition and the ability to perform ADLs (all $p<0.001)$ [43]. For the subgroup $(n=70)$ who were able to self-report at 18 months, mean QoL was not significantly different from baseline, although there was a wide variation in results, with $40 \%$ reporting a decline on the DEMQOL 
and 57\% reporting improvement; the proxy evaluations showed similar percentages of decline and improvement [43]. Changes in dependence were not associated with QoL [43]. In addition, patient-reported QoL was not correlated with disease severity, as measured by changes in cognition, neuropsychiatric symptoms, or ADL capabilities, although there was a weak correlation between proxy-rated QoL and neuropsychiatric symptoms $\quad(r=-0.29$, $p<0.01$ ) [43]. However, since the subgroup only included those patients who were capable of self-reporting at 18 months, patients who experienced significant deterioration were not included, which could have biased the results [43].

\section{ADL Using Disease- or Dementia-Specific Instruments}

As noted previously, the ability to perform ADLs is an important component of QoL $[11,12]$. Declining ADL skills can have a negative effect on QoL, as shown in the study of French patients with clinically diagnosed mild to moderate $\mathrm{AD}$ dementia, in which patients who could still perform ADLs such as using the telephone $(p=0.05)$ had significantly higher scores on the self-esteem domain of the DQoL than patients who could not [22]. As with the measurement of overall QoL, it has been recommended that measurement of ADLs be performed with instruments that have dementiaspecific measures, such as the Disability Assessment for Dementia (DAD) or Alzheimer's Disease Cooperative Study-Activities of Daily Living (ADCS)-ADL $[14,48]$. A recent analysis of ADL in patients with clinically diagnosed AD dementia $(n=185)$ found that cognition (as assessed by the MMSE and the Symbol Digit Modalities Test [SMDT]) was not associated with basic ADL (e.g., self-feeding, personal hygiene, getting dressed) but was associated with total ADL, which also included activities such as telephone use, reading, managing finances, and dong chores) [48].

Factors unrelated to dementia can affect ability for ADLs. For example, some ADLs may never have been performed prior to dementia onset (e.g., cooking), and comorbid non-dementia-related medical issues may decrease ADL ability [14]. A study of patients with mild AD and with $(n=113)$ or without diabetes $(n=859)$ showed that after 18 months, while there was no difference between the groups in terms of changes in cognition or QoL (on the QoL-AD or EQ-5D), patients with $\mathrm{AD}$ and comorbid diabetes had significantly less deterioration in ADLs $[49,50]$.

A broader concept relating to ADLs is that the inclusion of activities such as social interaction and hobbies can have an important impact on QoL [51]. A UK study of patients with mild AD and their caregivers evaluated impairment in IADLs, QoL, and cognition from this viewpoint [51]. The study also attempted to differentiate between the key but separate abilities of initiating an action versus performing the action [51]. The results showed that patients had greater deficits in performance of IADLs compared to initiating IADLs, with the exception of engaging in hobbies and maintaining an active social life [51]. However, the deficits in these latter two IADLs were correlated with worse QoL and were also a reason for caregiver stress [51].

Some studies have evaluated methods of predicting deficits in ADLs. For example, a study in Canadian patients with dementia evaluated the effects of cognitive fluctuations (sudden and variable decreases in their already reduced cognition and attention) on ADLs and QoL [52]. The results showed that cognitive fluctuations were significantly associated with decreases in ADLs on the Alzheimer's Disease FunctionalAssessment Scale-Activities of Daily Living (ADFACS-ADL) and in QoL as measured by the Quality of Life in Late-Stage Dementia Scale (QUALID) [52]. While no correlation was seen with IADLs, the investigators noted that because of the severity of dementia, IADLs were already severely limited in these patients [52]. A US study of patients with clinically diagnosed $\mathrm{AD}$ dementia evaluated the predictive value of patient versus caregiver reports of depressive symptoms for deficits in IADLs [53]. Results showed that self-report of depressive symptoms was more accurate than caregiver report of depressive symptoms in predicting deficits in IADLs over and above IADL deficits due to declines in cognitive function [53]. 
ADL impairment has also been suggested as a tool for predicting risk for development of AD. People who develop MCI or AD may first notice a decline in their cognitive abilities (SCD), although their cognitive performance testing results remain normal [54]. Data from the German Study on Ageing, Cognition, and Dementia in Primary Care Patients (AgeCoDe) were analyzed to determine whether a decline in IADLs in conjunction with SCD could help identify patients who would progress to $\mathrm{AD}$ [54]. Over a 10.5-year follow-up period, $10.7 \%$ of participants $(157 / 1467)$ developed AD [54]. Risk for AD was highest in those with both SCD and impaired IADLs (hazard ratio [HR] 6.1, 95\% CI: 2.9, 13.0); after adjustment for demographics, lifestyle, and health, the HR was 2.5 (95\% CI: 1.1, 5.7) [54]. In this study, both MCI and $\mathrm{AD}$ dementia were diagnosed based on clinical criteria [54].

\section{Utilities in $A D$}

An SLR found that the most common instruments used to assess utilities in patients with $\mathrm{AD}$ were the general tools EQ-5D, Health Utilities Index Mark 2 (HUI2) and Mark 3 (HUI3), Quality of Well-Being (QWB), Assessment of Quality of Life (AQoL), and 15D, and the dementia-specific tool DEMQOL-U [55]. However, there is little consensus among investigators as to whether a general or specific instrument is best for patients with dementia.

The SLR found the general EQ-5D to be the most appropriate instrument for patients with dementia due to its high scores in terms of feasibility (willingness/ability to complete assessment), reliability, and responsiveness, and its moderate to strong validity [55]. The HUI2 and HUI3 also scored strongly in terms of feasibility and reliability, but because they have no ceiling or floor effects, the QWB and the AQoL had the highest precision [55]. The QWB scored highly in terms of validity because it includes the most items of interest to patients with dementia and their caregivers [55]. The DEMQOL-U, despite being a dementia-specific scale, scored poorly in every category [55].

A study that compared the use of the dementia-specific QoL-AD and the general instrument HUI3 found that HUI3 results had a stronger correlation with other outcome measures, including functional abilities, cognition, dependence, and behavior, than the QoL-AD [56]. Other researchers have noted that while it is a general instrument, the HUI3 includes domains such as speech and cognition that are important for patients with dementia [57].

In contrast, other studies have questioned the use of general instruments in patients with dementia. A recent analysis of patients with dementia and their caregivers ( $n=560$ dyads) in which EQ-5D utilities were compared with QoL$\mathrm{AD}$ scores highlighted some limitations of the EQ-5D-3L in this population [58]. Most notably, both EQ-5D-3L utilities and EQ-5D VAS were strongly correlated with patient-rated QoL-AD scores ( $r=0.644$ and $r=0.553$, respectively), but were only weakly correlated with proxyrated QoL-AD scores $(r=0.314$ and $r=0.170$, respectively), suggesting that the EQ-5D has the same limitations as other patient-reported measures of QoL [58]. The EQ-5D-3L also had a notable ceiling effect ( $18 \%$ of patients had the highest score on the EQ-5D-3L compared with $<1 \%$ of patient QoL-AD scores). However, some properties of the EQ-5D were acceptable (e.g., acceptability, discriminative abilityi.e., ability to differentiate among health states-and convergent validity) [58]. A similar study demonstrated that depression adversely impacted QoL in patients with clinically diagnosed MCI [59].

\section{Economic Burden of AD}

The considerable total societal economic burden of AD includes direct costs (including both medical and non-medical costs) and indirect costs (largely informal care costs, but also lost productivity costs and intangible costs) $[7,60,61]$. While the precise definitions of different cost categories varied across studies, it was generally the case that direct medical costs included costs for physician and other outpatient services, emergency department (ED) visits, hospitalizations, and/or pharmacy costs. By contrast, direct non-medical costs (often described as social care costs) included community care service costs, costs for 
consumables, costs for home modifications, and costs for institutionalization. Finally, indirect costs included lost productivity costs for patients and caregivers as well as informal care costs (i.e., the value of unpaid care provided by family members). The total societal burden of AD dementia was estimated at more than \$307 billion in the USA in 2010, 91.4 billion renminbi (RMB) in China in 2010, €232 billion in Europe (European Union [EU] 28) in 2015, and $\$ 958$ billion worldwide [4-7]. By 2050, these costs are projected to increase by approximately 4.9-fold in the USA (to $\$ 1.5$ trillion), 3.6-fold in China (to 332.5 billion RMB), 2.7-fold in Europe (to $€ 633$ billion), and 9.5-fold worldwide (to $\$ 9.1$ trillion) [4-7]. These estimated cost increases are driven by increases in the prevalence of $\mathrm{AD}$ dementia as a result of population aging as well as increased per-patient costs [4-7]. Notably, the two models that provided cost breakdowns differed considerably in included cost inputs: the US model estimated that $41 \%$ of the 2010 total societal burden was due to informal care costs, whereas the Chinese model estimated that paid home caregivers accounted for $70 \%$ of the total cost burden and did not incorporate the contribution of unpaid, informal care by family members $[5,7]$. These findings are broadly consistent with a worldwide study evaluating the burden of dementia (i.e., not exclusively due to $\mathrm{AD}$ ), which estimated a worldwide burden of $\$ 604$ billion in 2010 and $\$ 818$ billion in 2015 , with informal care costs accounting for $36 \%$ of total costs in 2010 and 40\% in 2015 [62]. In this model, approximately $90 \%$ of total costs were incurred in high-income countries. The following sections report on per-patient costs associated with $\mathrm{AD}$, including key cost drivers such as dementia severity, and on resource use by patients with AD. Total societal costs are considered as well as the underlying component costs.

\section{Total Societal Cost of AD Dementia and Key Cost Drivers}

Total societal costs per patient per month (PPPM) incurred by patients with clinically diagnosed $\mathrm{AD}$ dementia from six countries are reported in Table 2. Monthly costs reported in US dollars varied from $\$ 1595$ (China) to $\$ 5941$ (USA); those reported in euros varied from $€ 1852$ (France) to $€ 5363$ (one of two estimates

Table 2 Total societal cost (PPPM) incurred by patients with AD dementia

\begin{tabular}{lll}
\hline Author, year (study name) & Setting & Total societal cost (PPPM) \\
\hline Zissimopoulos, 2014* & USA & $\$ 5941^{\ddagger}$ \\
Henderson, 2019 (IDEAL) & UK & $£ 1166^{\dagger \dagger}$ \\
Reed, 2017 (GERAS) & UK & $€ 1806^{\dagger}(€ 2106)^{\dagger}$ \\
& France & $€ 1852^{\dagger}$ \\
Maresova, 2018 (meta-analysis) & Germany & $€ 2122^{\dagger}$ \\
Olazaran, 2017 (GERAS II) & France, Spain & $€ 3895$ \\
Darba, 2015 & Spain & $€ 2190$ \\
Nakanishi, 2020 (GERAS-J) & Spain & $€ 5363^{* *}$ \\
Jia, 2018 & Japan & $\mathrm{JPY} 224,584(\$ 2101)$ \\
\hline
\end{tabular}

AD Alzheimer disease, GERAS Geriatric Education and Research in Aging Sciences, PPPM per patient per month, UK United Kingdom, USA United States

${ }^{*}$ Model-based estimate of per-patient costs for patients aged $\geq 70$ years with AD dementia

Costs reported over longer time frames $\left(18\right.$ months $^{\dagger}, 12$ months $^{\ddagger}, 6$ months $^{* *}$, or 3 months $\left.{ }^{\dagger \dagger}\right)$ were adjusted as appropriate to generate monthly costs 
Table 3 Total societal cost (PPPM) incurred by patients with AD, stratified by dementia severity

\begin{tabular}{|c|c|c|c|c|c|}
\hline \multirow[t]{2}{*}{ Author, year (study name) } & \multirow[t]{2}{*}{$\begin{array}{l}\text { Setting } \\
\end{array}$} & \multicolumn{4}{|c|}{ Total societal cost (per month) } \\
\hline & & Mild & Moderate & Moderate-to-severe & $p$ value \\
\hline \multirow{2}{*}{$\begin{array}{l}\text { Robinson, } 2020 \text { (GERAS- } \\
\text { US) }\end{array}$} & \multirow[t]{2}{*}{ USA } & $\$ 4243^{*}$ & - & - & - \\
\hline & & $\$ 2653^{\dagger}$ & - & - & - \\
\hline \multirow[t]{3}{*}{ Reed, 2017 (GERAS) } & France & $€ 1327^{\star}$ & $€ 1878^{*}$ & $€ 2328^{\ddagger}$ & NR \\
\hline & Germany & $€ 1445 \ddagger$ & $€ 2357 \ddagger$ & $€ 2830^{*}$ & NR \\
\hline & UK & $€ 1676 \ddagger$ & $€ 2002 \ddagger$ & $€ 2822^{*}$ & NR \\
\hline Lenox-Smith, 2016 (GERAS) & UK & $£ 1437^{\star}$ & $£ 1717^{\star}$ & $£ 2420^{*}$ & $<0.001$ \\
\hline $\begin{array}{l}\text { Maresova, } 2018 \text { (meta- } \\
\text { analysis) }\end{array}$ & $\begin{array}{l}\text { France, } \\
\text { Spain }\end{array}$ & $€ 2668$ & - & $€ 5270$ & NR \\
\hline Rapp, 2018 (GERAS) & France & $€ 1341^{*}$ & $€ 1905^{*}$ & $€ 2454^{*}$ & $<0.001$ \\
\hline Bruno, 2018 (GERAS II) & Italy & $€ 1850$ & $€ 1552$ & $€ 2728$ & $<0.001$ \\
\hline Chiatti, 2015 & Italy & - & $€ 1677^{* *}$ & - & NA \\
\hline Olazaran, 2017 (GERAS II) & Spain & $€ 1514$ & $€ 2082$ & $€ 2818$ & $<0.001$ \\
\hline Darba, $2015^{* * *}$ & Spain & $€ 2623^{\dagger \dagger}$ & $€ 5765^{\dagger \dagger}$ & $€ 8746^{\dagger \dagger, \text { 林 }}$ & $<0.001$ \\
\hline Nakanishi, 2020 (GERAS-J) & Japan & $\begin{array}{l}\text { JPY } 158,454 \\
\quad(\$ 1483)\end{array}$ & $\begin{array}{l}\text { JPY } 211,302 \\
\quad(\$ 1977)\end{array}$ & $\begin{array}{l}\text { JPY 294,224 } \\
\quad(\$ 2753)\end{array}$ & $\mathrm{NR}^{\dagger \dagger \dagger}$ \\
\hline Jia, 2018; Yan, 2019 & China & $\$ 1133^{* *}$ & $\$ 1399^{* *}$ & $\$ 2167^{* *},+$ & $<0.001$ \\
\hline
\end{tabular}

$A D$ Alzheimer disease, CDR Clinical Dementia Rating, GERAS Geriatric Education and Research in Aging Sciences, MMSE Mini-Mental State Exam, $N A$ not applicable, $N R$ not reported, PPPM per patient per month, UK United Kingdom ${ }^{*}$ Caregiver costs calculated using opportunity cost method, in which hours of lost productivity are multiplied by average annual gross hourly wage for workers and lost leisure time (valued at 35\% of hourly worker wage) for non-workers

${ }^{\dagger}$ Caregiver costs calculated using replacement cost method, in which hours of lost productivity are multiplied by professional caregiver/aide hourly wage

Costs reported over longer time frames ( 18 months ${ }^{*}, 12$ months $^{* *}$, or 6 months ${ }^{\dagger \dagger}$ ) were adjusted as appropriate to generate monthly costs

tt Costs for patients with severe AD dementia, rather than moderate-to-severe AD dementia

${ }^{* * *}$ Severity was indicated by CDR score of 1 (mild), 2 (moderate), or 3 (severe), rather than by MMSE score as with other studies in this table

${ }^{\dagger \dagger}$ While no $p$ value was provided, these results were described as significant and had $95 \%$ confidence intervals that did not overlap, indicating significance

from Spain) [6, 7, 44, 63-66]. Two UK studies reported different monthly total cost estimates ( $£ 1160$ and $£ 1806$ ), as did two studies conducted in Spain (€2190 and €5363) $[44,64,66,67]$. The substantial gap between the two studies conducted in Spain may be due to differences in dementia severity between populations, although the studies used different metrics for assessing severity, preventing direct comparisons [44, 64]. Olazaran et al., who assessed dementia severity by MMSE score, reported that $38.4 \%$ of patients had moderateto-severe $\mathrm{AD}$ dementia, whereas Darba et al. assessed severity by Clinical Dementia Rating (CDR) score and reported that $30.4 \%$ of patients had severe $\mathrm{AD}[44,64]$. Of note, the analysis by 
Zissimopoulos et al. estimated that total societal costs were considerably higher among patients with AD than among those who did not have AD (\$5941 vs. \$1531) [7].

Potential drivers of total societal costs in patients with $\mathrm{AD}$ dementia include dementia severity, patient dependence level, cognitive and/or functional decline, institutionalization, and comorbidity burden.

Studies conducted in the USA, EU5 countries (France, Germany, Italy, Spain, and the UK), Japan, and China found that costs rise with increasing severity of AD dementia (Table 3). These studies included national cohorts from the GERAS (France, Germany, and UK), GERAS II (Spain and Italy), GERAS-J (Japan), and GERAS-US prospective studies as well as two cross-sectional studies (Spain, China), an analysis of baseline data from a randomized controlled trial (RCT) set in Italy, and a metaanalysis of three studies conducted in France and Spain [63-66, 68-72]. In all studies reporting on dementia severity strata, patients with moderate-to-severe or severe dementia incurred higher total societal costs than those with mild or moderate dementia, and the difference between severity groups was statistically significant in all studies where significance was reported [64-66, 68, 70, 71]. Of note, one study, conducted in Italy, found that among patients with $\mathrm{AD}$, those with moderate dementia incurred lower total societal costs than those with mild dementia [68].

Dependence level and cognitive or functional decline are associated with total societal costs in patients with AD dementia. Studies conducted in the USA, UK, and Spain found that as the level of functional dependence increased, total societal costs also rose [73-75]. The three studies used different methods of assessing dependence level, with the UK study mapping dependence levels of 0 to 5 based on ADCS-ADL questionnaire responses (the cost difference from dependence level 1 to dependence level 5 was €2844 PPPM, $p<0.001$ ) and the other studies using Dependence Scale (DS) scores to stratify patients into four dependence levels (the Spanish study; cost difference from the lowest to highest dependence level was $€ 7133$ PPPM, $p<0.001)$ or six dependence levels (the US study; cost difference from the lowest to highest dependence level was \$5401 PPPM) [73-75]. An analysis of patients from the GERAS study in France, Germany, and the UK found that those with cognitive decline $(\geq 3$ point decline from baseline MMSE score) or functional decline (decline in performance of $\geq 20 \%$ of ADCS-ADL items) exhibited significantly increased total societal costs compared to patients who did not experience such declines (for cognitive decline, $€ 1653$ vs. $€ 1210$, $p=0.045$; for functional decline, $€ 1660$ vs. $€ 945, p<0.001)$ [76]. An evaluation of cognitive decline in patients with mild $\mathrm{AD}(n=200)$ from the UK cohort of the GERAS study found that a 3.6-point reduction in MMSE score over the 18-month study period was associated with an increase in total societal costs of approximately $£ 124$ per month [77]. In the French arm of the GERAS study, a 1-point reduction in MMSE score (indicative of worsening cognitive function) was associated with higher total societal costs $(2.2 \%$ increase; $p<0.01)$ [70].

Institutionalization and comorbidity burden have also been associated with total societal costs in patients with $\mathrm{AD}$ dementia. A model evaluating the relationship between time to institutionalization and total societal costs estimated that total societal costs rose from $£ 1900$ at 5 years before institutionalization to $£ 3160$ at institutionalization [78]. A study conducted in China reported that total societal costs rose as the number of comorbidities rose; PPPM costs rose from $\$ 1145$ for patients with no comorbidities to $\$ 3196$ for those with $\geq 5$ $(p<0.001)$ [71]. The association between costs and comorbidity number was also observed in patients stratified by AD severity $(p<0.001$ for difference across mild, moderate, and severe dementia strata) [71].

\section{Total Direct Cost of AD Dementia and Key Cost Drivers}

Direct costs PPPM incurred by patients with clinically diagnosed AD dementia from seven countries are reported in Table 4. Monthly total costs reported in US dollars varied from \$1479 (China) to $\$ 3506$ (USA), those reported in euros varied from $€ 312$ to $€ 878$ (both estimates from Spain), those reported in British pounds varied 
Table 4 Total direct cost (PPPM) incurred by patients with AD dementia

\begin{tabular}{lllll}
\hline Author, year (study name) & Setting & \multicolumn{2}{l}{ Direct costs (per month) } \\
\cline { 2 - 4 } & & Total & Medical & Non-medical (i.e., social care) \\
\hline Chen, 2019 & USA & $\$ 1161^{*}$ & - & - \\
Zissimopoulos, 2014 & USA & $\$ 3506^{*}$ & - & - \\
Bayen, 2020 & USA & $\$ 1601^{*}$ & - & - \\
Pyenson, 2019 & USA & $\$ 1601^{*}$ & - & - \\
Desai, 2019 & USA & - & $\$ 1473^{*, * *,+\sharp}$ & - \\
Bruggenjurgen, 2015 & Germany & $€ 855^{*}$ & - & - \\
Henderson, 2019 (IDEAL) & UK & $£ 284^{\ddagger}$ & - & - \\
Jones, 2015 & UK & $£ 1339^{\ddagger}$ & $£ 365^{\ddagger}$ & $£ 975^{\ddagger}$ \\
Maresova, 2018 (meta-analysis) & France, Spain & - & $€ 313$ & $€ 1398$ \\
Olazaran, 2017 (GERAS II) & Spain & $€ 878^{\dagger \dagger}$ & $€ 289$ & $€ 589$ \\
Darba, 2020 & Spain & $€ 449^{*}$ & - & - \\
Darba, 2015 & Spain & $€ 312^{\dagger, \mathrm{C}}$ & $€ 171^{\dagger}$ & $€ 141^{\dagger}$ \\
Nakanishi, 2020 (GERAS-J) & Japan & $\mathrm{JPY} 95,923^{\dagger \dagger}$ & $\mathrm{JPY} 26,744$ & $\mathrm{JPY} 69,179$ \\
Takechi, 2019 & Japan & - & - & $\mathrm{JPY} 81,970$ \\
Jia, 2018; Yan, 2019 & China & $\$ 789^{*, \dagger \dagger}$ & $\$ 531^{*}$ & $\$ 258^{*}$ \\
\hline
\end{tabular}

$A D$ Alzheimer disease, ED emergency department, GERAS Geriatric Education and Research in Aging Sciences, PPPM per patient per month, UK United Kingdom, USA United States

Costs reported over longer time frames (12 months* 6 months ${ }^{\dagger}$, or 3 months $\left.s^{*}\right)$ were adjusted as appropriate to generate monthly costs

${ }^{* *}$ Includes hospitalization and ED costs but not outpatient and drug costs

${ }^{\dagger}$ Based on addition of medical and non-medical costs

$\$$ Reports costs incurred during the year prior to diagnosis of $\mathrm{AD}$ dementia

from $£ 284$ to $£ 1339$ (both estimates from UK), and a study from Japan reported a total cost of JPY (Japanese yen) 95,923 [6, 7, 44, 64, 65, $67,79-84]$. Studies from six countries reported on direct medical costs, which varied from $\$ 531$ (China) to $\$ 1473$ (USA), $€ 171$ (Spain) to $€ 313$ (France and Spain), £365 (UK), and JPY 26,744 (Japan) [6, 44, 63-65, 81, 85]. Finally, direct non-medical costs (i.e., social care costs such as home health assistance, community care, skilled nursing facility care, consumables), reported in five countries, were $€ 141$ to $€ 589$ (Spain), $€ 1398$ (meta-analysis of France and Spain), £975 (UK), \$258 (China), and JPY 69,179 to JPY 81,970 (Japan) [6, 44, 63-65, 81, 86]. Among studies reporting on direct medical and nonmedical costs, three studies and a meta-analysis reported that non-medical costs were higher ( $₫ 975$ vs. $£ 365$ in a UK study, $€ 589$ vs. $€ 289$ in a Spanish study, JPY 69,179 vs. JPY 26,744 in a Japanese study, and $€ 1398$ vs. $€ 313$ in a metaanalysis), whereas two studies reported that direct medical costs were higher than nonmedical costs ( $€ 171$ vs. $€ 141$ in another Spanish study and $\$ 1055$ vs. \$424 in a Chinese study). The cause of these differences is unclear, but it may have to do with differences in cost classification or differences between study populations. Notable differences were also seen between a database study conducted in the USA, 
Table 5 Total direct cost (PPPM) incurred by patients with AD, stratified by dementia severity

\begin{tabular}{|c|c|c|c|c|c|}
\hline \multirow[t]{2}{*}{ Author, year (study name) } & \multirow[t]{2}{*}{ Setting } & \multicolumn{4}{|c|}{ Total direct costs (per month) } \\
\hline & & Mild & Moderate & Moderate-to-severe & $p$ value \\
\hline \multicolumn{6}{|l|}{ Total direct costs } \\
\hline Ton, $2017^{+\neq, * * *}$ & USA & $\$ 2694^{*}$ & $\$ 1672^{*}$ & $\$ 4722^{*, \dagger \dagger}$ & $<0.001$ \\
\hline Rapp, 2018 (GERAS) & France & $€ 644^{\dagger}$ & $€ 903^{\dagger}$ & $€ 1193^{\dagger}$ & NR \\
\hline Lenox-Smith, 2016 (GERAS) & UK & $£ 559^{\dagger}$ & $£ 805^{\dagger}$ & $£ 1032^{\dagger}$ & NR \\
\hline Chiatti, 2015 & Italy & - & $€ 545^{\star}$ & - & NR \\
\hline Olazaran, 2017 (GERAS II) & Spain & $€ 464$ & $€ 844$ & $€ 1238$ & NR \\
\hline Darba, $2015^{\text {t末 }}$ & Spain & $€ 183^{* *}$ & $€ 333^{* *}$ & $€ 427^{* *}$ & NR \\
\hline Nakanishi, 2020 (GERAS-J) & Japan & JPY 70,347 & JPY 94,812 & JPY 118,380 & NR \\
\hline \multicolumn{6}{|l|}{ Direct medical costs } \\
\hline Rapp, 2018 (GERAS) & France & $€ 285^{\dagger}$ & $€ 395^{\dagger}$ & $€ 451^{\dagger}$ & NR \\
\hline Lenox-Smith, 2016 (GERAS) & UK & $£ 161^{\dagger}$ & $£ 174^{\dagger}$ & $£ 170^{\dagger}$ & 0.624 \\
\hline Maresova, 2018 (meta-analysis) & France, Spain & $€ 280$ & - & $€ 278$ & NR \\
\hline Olazaran, 2017 (GERAS II) & Spain & $€ 272$ & $€ 236$ & $€ 346$ & 0.320 \\
\hline Darba, $2015^{\text {林 }}$ & Spain & $€ 151^{* *}$ & $€ 151^{* *}$ & $€ 225^{* *}$ & 0.02 \\
\hline Nakanishi, 2020 (GERAS-J) & Japan & JPY 27,441 & JPY 26,309 & JPY 26,649 & NR \\
\hline \multicolumn{6}{|l|}{ Direct non-medical costs } \\
\hline Rapp, 2018 (GERAS) & France & $€ 359^{\dagger}$ & $€ 508^{\dagger}$ & $€ 742^{\dagger}$ & NR \\
\hline Lenox-Smith, 2016 (GERAS) & UK & $£ 398^{\dagger}$ & $£ 631^{\dagger}$ & $£ 862^{\dagger}$ & $<0.001$ \\
\hline Maresova, 2018 (meta-analysis) & France, Spain & $€ 619$ & - & $€ 1705$ & NR \\
\hline Olazaran, 2017 (GERAS II) & Spain & $€ 192$ & $€ 608$ & $€ 892$ & $<0.001$ \\
\hline Darba, $2015^{*+}$ & Spain & $€ 32^{* *}$ & $€ 183^{* *}$ & $€ 202^{* *}$ & $<0.001$ \\
\hline Nakanishi, 2020 (GERAS-J) & Japan & JPY 42,906 & JPY 68,503 & JPY 91,731 & NR \\
\hline
\end{tabular}

$A D$ Alzheimer disease, CDR Clinical Dementia Rating, GERAS Geriatric Education and Research in Aging Sciences, MMSE Mini-Mental State Exam, NR not reported, NS not significant, PPPM per patient per month, UK United Kingdom, USA United States

Costs reported over longer time frames ( 24 months $^{*}, 18$ months $^{\dagger}, 12$ months $s^{\ddagger}$, or 6 months $s^{* *}$ ) were adjusted as appropriate to generate monthly costs

${ }^{\dagger}$ Costs for patients with severe AD dementia, rather than moderate-to-severe AD dementia

W Severity of dementia was indicated by CDR score, rather than by MMSE score as with other studies in this table

${ }^{* * *}$ Costs reported here are excess costs beyond those incurred by a control group 
which reported a total cost direct burden of \$1161 PPPM, and a US model, which estimated a considerably higher burden of \$3506 PPPM. Among the five studies that reported on cost comparisons between patients with $\mathrm{AD}$ dementia and controls, all reported that direct costs were higher among patients with dementia. According to a recent retrospective database analysis conducted in the USA, which followed patients newly diagnosed with $\mathrm{AD}$ dementia $(n=16,454)$ and matched controls, direct medical costs were comparable between groups for most of the 3 years prior to diagnosis, but rose considerably in the $\mathrm{AD}$ dementia group during the 6 months prior to diagnosis (AD dementia group: \$1742 PPPM vs. control group: $\$ 806$ PPPM; $p<0.0001$ ) [87].

Potential drivers of direct costs in patients with $\mathrm{AD}$ include dementia severity, patient dependence level/care need, cognitive and/or functional decline, institutionalization, comorbidity burden, treatment status, age, and agitation.

Studies conducted in the EU5 countries (France, Germany, Spain, and the UK), Japan, China, and the USA found that total direct costs rose with increasing AD severity (Table 5). These studies included national cohorts from the GERAS (France, Germany, and UK), GERAS II (Spain and Italy), and GERAS-J (Japan) prospective studies as well as two cross-sectional studies (USA, Spain) and a meta-analysis $[44,63-65,70,88,89]$. Patients with moderateto-severe or severe AD dementia tended to incur higher total direct, medical, and non-medical costs than those whose dementia was mild or moderate, although tests of statistical significance were often not conducted. Dementia severity was associated with direct non-medical costs in each of the three studies that assessed this (all $p<0.001$ ) but was associated with direct medical costs in only one of the three studies $(p=0.02)[44,64,88]$. A systematic review identified seven studies that reported on total direct costs stratified by $\mathrm{AD}$ severity in Europe or the USA; of these, all but one study reported higher costs in patients with more severe $\mathrm{AD}$ dementia [90].

Dependence level and cognitive decline have been associated with direct costs
$[70,73-75,81,86]$. Studies conducted in France, Spain, Japan, the UK, and the USA found that as the level of functional dependence increased, direct costs also rose $[70,73-75,81,86]$. In the US study, which used the DS to stratify the patient population into six dependence levels from very mild to very severe, total direct, direct medical, and direct non-medical (i.e., social care) costs rose with increasing dependence, with the steepest rise seen in the non-medical costs related to long-term care [75]. A UK study, which focused on direct medical costs, found that those costs increased significantly $(p<0.001)$ over five levels of dependence; the magnitude of the increase (from $€ 295$ to $€ 616$ PPPM) was lower than that seen in the US study (\$377 to \$1120 PPPM) [74, 75]. Another UK study also found that non-medical costs accounted for most of the direct cost increase in patients at higher dependence levels (increase from highest to lowest dependence, PPPM $£ 136$ in direct medical costs vs. $£ 2166$ in non-medical costs) [81]. By contrast, the study conducted in Spain found that dependence was associated with significant increases in both medical (from $€ 625$ to $€ 1722, p<0.001$ ) and social care (from $€ 138$ to $€ 1432, p<0.001)$ costs [73]. An analysis of the French cohort of the GERAS study found that cognitive decline (1-point decrease in MMSE score) during the 18-month study was associated with a $2.5 \%$ increase in patient costs $(p<0.001)$ [70]. A study conducted in Japan found that when patients were stratified by care need, monthly social care costs rose with increasing need, from JPY 11,529 to JPY 233,584 $(p<0.001)$ [86].

Institutionalization and the cost impact of treatment have also been associated with direct costs $[78,91,92]$. A model evaluating the relationship between time to institutionalization and total societal costs estimated that total monthly direct costs rose from $£ 770$ at 5 years before institutionalization to $£ 1529$ at institutionalization, with healthcare costs accounting for relatively little of the increase ( $£ 283$ to $£ 348$ ) [78]. Two retrospective database analyses conducted in the USA found that direct costs were higher among patients with clinically diagnosed $\mathrm{AD}$ dementia aged 65 to 100 years who received a Food and Drug Administration 
(FDA)-approved treatment compared with those who did not $[91,92]$. One study found that total direct costs were significantly higher among untreated patients (PPPM costs $\$ 2509$ vs. \$2152, $p=0.0162)[91,92]$. The other analysis, which also stratified patients by age and timing of treatment initiation, found that patients aged 65 to 100 years who were not treated incurred higher costs than those who were treated (PPPM costs: untreated: \$2744, treated: \$2029 to $\$ 2706$ depending on timing of treatment initiation) [92]. Similar findings were seen among patients with AD dementia aged 50 to 64 years (PPPM costs: untreated: \$3807, treated: $\$ 1754$ to $\$ 2303$ depending on timing of treatment initiation), although the difference between treated and untreated patients was more pronounced [92].

An analysis of data from a prospective study conducted in the UK found that agitation was a key driver of direct costs (including medical and social costs) in patients with $\mathrm{AD}$ dementia $(n=695)$ [93]. Patients with no agitation incurred a monthly cost of $£ 2415$, whereas those with agitation incurred significantly greater monthly costs of $£ 2600$ to $£ 4572$ (costs adjusted for demographic and medical characteristics) $(p=0.01)$ [93].
Total Indirect Cost of AD Dementia and Key

\section{Cost Drivers}

Total PPPM informal care costs (i.e., costs associated with unpaid caregiving, typically by family members) incurred by patients with $\mathrm{AD}$ dementia from five countries are reported in Table 6. Other indirect costs (i.e., patient or caregiver lost productivity costs and intangible costs due to mental suffering and unexpected injuries) were not well reported. Monthly costs reported in US dollars varied from $\$ 786$ (China) to $\$ 2436$ (USA), and those reported in euros varied from $€ 1312$ to $€ 5539$ (two estimates from Spain and one from a meta-analysis of studies conducted in France and Spain) $[6,7,44$, $63,64]$. One UK study reported a monthly cost of $£ 864$ and a study in Japan reported a monthly cost of JPY $128,661[65,67]$. Only two studies reported on other types of indirect costs, a Chinese study which found that patients incurred $\$ 47$ per month in intangible costs and a Spanish study that found an indirect cost of $€ 77$ per month due to lost caregiver productivity $[6,64]$. The US analysis was based on a model in patients with $\mathrm{AD}$ dementia who were $\geq 70$ years of age; this analysis estimated that monthly costs in patients who did not have $\mathrm{AD}$ were considerably lower than in those with AD dementia (\$247 vs. \$2436) [7].

Table 6 Total informal care and other indirect cost (PPPM) incurred by patients with AD dementia

\begin{tabular}{llll}
\hline Author, year (study name) & Setting & Informal care costs & Other indirect costs \\
\hline Zissimopoulos, 2014** & USA & $\$ 2436^{*}$ & $\mathrm{NR}$ \\
Henderson, 2019 (IDEAL) & UK & $£ 864^{\ddagger}$ & $\mathrm{NR}$ \\
Maresova, 2018 (meta-analysis) & France, Spain & $€ 1556$ & $\mathrm{NR}$ \\
Olazaran, 2017 (GERAS II) & Spain & $€ 1312$ & $\mathrm{NR}$ \\
Darba, 2015 & Spain & $€ 5539^{\dagger}$ & $€ 77^{\dagger}$ \\
Nakanishi, 2020 (GERAS-J) & Japan & $\mathrm{JPY} 128,661$ & $\mathrm{NR}$ \\
Jia, 2018 & China & $\$ 760^{*}$ & $\$ 47^{*, \dagger \dagger}$ \\
\hline
\end{tabular}

AD Alzheimer disease, GERAS Geriatric Education and Research in Aging Sciences, NR not reported, PPPM per patient per month, UK United Kingdom, USA United States

Costs reported over longer time frames $\left(12\right.$ months* 6 months ${ }^{\dagger}$ or, or 3 months $\left.{ }^{\dagger}\right)$ were adjusted as appropriate to generate monthly costs

** Model-based estimate of per-patient costs for patients aged $\geq 70$ years with AD dementia

${ }^{\dagger \dagger}$ Cost of mental suffering of caregivers and unexpected injuries 
Table 7 Informal care cost (PPPM) incurred by patients with AD, stratified by dementia severity

\begin{tabular}{llllll}
\hline Author, year (study name) & \multirow{2}{*}{ Setting } & \multicolumn{2}{l}{ Informal care cost (per month) } \\
\cline { 3 - 6 } & & Mild AD & Moderate AD & Moderate-to-severe AD & $\boldsymbol{p}$ value \\
\hline Lenox-Smith, 2016 (GERAS) & UK & $£ 871^{*}$ & $£ 945^{*}$ & $£ 1371^{*}$ & $<0.001$ \\
Rapp, 2018 (GERAS) & France & $€ 698^{*}$ & $€ 1002^{*}$ & $€ 1261^{*}$ & $<0.001$ \\
Maresova, 2018 (meta-analysis) & France, Spain & $€ 1027$ & - & $€ 1996$ & NR \\
Bruno, 2018 (GERAS II) & Italy & $€ 1370$ & $€ 1223$ & $€ 2223$ & $<0.001$ \\
Chiatti, 2015 & Italy & - & $€ 1677^{\dagger}$ & - & NA \\
Olazaran, 2017 (GERAS II) & Spain & $€ 1050$ & $€ 1239$ & $€ 1580$ & 0.013 \\
Darba, 2015 & Spain & $€ 2760$ & $€ 5983$ & $€ 8817^{\dagger * * *}$ & $<0.001$ \\
Nakanishi, 2020 (GERAS-J) & Japan & JPY 88,107 & JPY 116,488 & JPY 175,845 & NR \\
\hline
\end{tabular}

$A D$ Alzheimer disease, CDR Clinical Dementia Rating, GERAS Geriatric Education and Research in Aging Sciences, MMSE Mini-Mental State Examination, NR not reported, PPPM per patient per month, UK United Kingdom, USA United States

Costs reported over longer time frames (18 months* 12 months $^{\dagger}$, or 6 months $\left.s^{\ddagger}\right)$ were adjusted as appropriate to generate monthly costs

${ }^{* *}$ Costs for patients with severe AD dementia, rather than moderate-to-severe AD dementia

${ }^{\dagger}$ Severity of dementia was indicated by CDR score of 1 (mild), 2 (moderate), or 3 (severe), rather than by MMSE score as with other studies in this table

Potential drivers of informal care costs in patients with $\mathrm{AD}$ dementia include dementia severity, patient dependence level, and comorbidity burden.

Studies conducted in EU countries (France, Italy, Spain, and the UK) and Japan found that informal care costs rose with increasing dementia severity (Table 7). These studies included national cohorts from the GERAS (France, and UK), GERAS II (Spain and Italy), and GERAS-J (Japan) prospective studies as well as a cross-sectional study (Spain), an analysis of baseline data from an RCT (Italy), and a metaanalysis [44, 63-65, 68-70, 88]. In all studies, patients with moderate-to-severe or severe $\mathrm{AD}$ dementia incurred higher informal care costs than those with less severe dementia, and the difference between groups was significant in the five studies that assessed significance. Of note, one study, conducted in Italy, found that patients with moderate $\mathrm{AD}$ dementia incurred lower informal care costs than those with mild AD dementia [68]. A systematic review identified six studies that reported on total indirect costs (related to caregiving and lost productivity) stratified by $\mathrm{AD}$ dementia severity in Europe or the USA, each of which reported higher costs in patients with more severe dementia [90].

Dependence level and behavioral symptoms have also been associated with informal care costs in patients with AD dementia. Studies conducted in the USA and Spain found that as the level of functional dependence (as assessed by the DS scale) increased, informal care costs also tended to rise $[73,75]$. In the US study, which stratified the patient population into six dependence levels from very mild to very severe, informal care costs (PPPM) rose from $\$ 46$ among patients with very mild dependence to a peak of \$2705 among those with moderate dependence. Informal care costs were lower among patients with severe (\$2051) and very severe dependence (\$1763), which may reflect a transition from informal to formal care at the highest dependence levels [75]. By contrast, the study conducted in Spain, which stratified patients into four dependence levels, found that dependence was associated with significant increases in monthly informal care costs (from 
$€ 2311$ to $€ 9639, p<0.001)$ costs [73]. An analysis of data from the GERAS study cohorts in France and Germany, for which the follow-up period was extended to 36 months, found that functional loss (as assessed by ADCS-ADL scores at baseline and at 18 months) was associated with increased informal care costs [94].

\section{Resource Use}

A clinical diagnosis of $\mathrm{AD}$ dementia (based on diagnostic codes in administrative claims data) was associated with increased healthcare resource use and increased need for informal care. Many of the studies previously discussed regarding costs associated with $\mathrm{AD}$ dementia also reported on increased resource use and/or informal care hours. For example, three studies conducted in the USA (two studies) and Germany found that patients with $\mathrm{AD}$ dementia incurred more resource use, including emergency department (ED) visits, hospitalizations, inpatient days, physician contacts, and/or prescriptions compared with controls [79, 85, 87]. In both US studies, the increased resource use occurred prior to diagnosis, including one study that found that the difference in hospitalizations and ED visits was statistically significant (both $p<0.01)[85,87]$. In the German study, patients diagnosed with $\mathrm{AD}$ dementia had more hospitalizations, inpatient days, physician contacts, and drugs prescribed (all $p<0.001$ ) compared with controls [79].

Several studies also found that increasing severity of $\mathrm{AD}$ dementia was associated with resource use [66, 70, 79, 88-90, 95]. A multinational (USA, Canada, and the EU5) survey examining resource use by people with $\mathrm{AD}$ $(n=6143)$ found that resource use rose with increasing AD severity [95]. For most elements of resource use assessed (primary care visits, other provider visits, and hospitalizations), resource use increased with rising dementia severity $(p<0.001)$, with the exception of specialist visits, which were less common among patients with severe dementia than in those with moderate dementia [95]. Studies conducted in the USA and UK have found that the severity of $\mathrm{AD}$ dementia is associated with risk of hospitalization (one study, $p<0.005$ ) and/or institutionalization (both $p<0.001$ ) $[88,89]$. Studies conducted in the UK, France, and Spain found that caregiver time rose with increasing severity of $\mathrm{AD}$ dementia (all significant, $p$ $\leq 0.03)$; an SLR identified three studies that reported similar findings [70, 88-90]. An analysis of the GERAS study (conducted in France, Germany, and the UK) found between-country differences in resource use by patients with $\mathrm{AD}$ dementia: for example, caregiver time was significantly higher in the UK (125 hours/month) and Germany (101 hours/month) than in France (89 hours/month; $p<0.001$ ), whereas hospitalizations were more frequent in France than in the UK or Germany $(p<0.001)$ [66]. Such differences may reflect differences in the health and social care systems in the different countries.

Two studies conducted in the USA found that $\mathrm{AD}$ dementia is a common driver of resource use, particularly due to institutionalization, but that this may be less costly than that used by patients with other diseases. An analysis of US hospital discharges from 2002 to 2012 (using the Nationwide Inpatient Sample [NIS]) demonstrated that a diagnosis of $\mathrm{AD}$ dementia was associated with increased risk of hospitalization (OR 1.07, 95\% CI 1.03, 1.11, $p<0.001)$ and increased hospital length of stay (LOS) (+0.8 days, $p<0.001$ ), although hospital charges were lower $(-\$ 5900, p<0.001)$, suggesting that $\mathrm{AD}$ dementia is a frequent cause of hospitalization among affected patients but the resultant hospital charges per discharge are lower than the average charges [96]. A retrospective analysis of Medicare claims data identified a cohort of patients with $\mathrm{AD}$ or related dementia with functional dependency and nursing home use as one of five high-need phenotypes among Medicare beneficiaries. This patient cohort was characterized by a high degree of institutionalization (only $59.4 \%$ of living days spent in the community), which led to a Medicare cost burden of $\$ 2395$ per month [97]. However, other high-need phenotypes identified in this study, such as comorbid ischemic heart disease with home care or hospitalization and skilled nursing facility use, were more costly. 
Key drivers of institutionalization in $\mathrm{AD}$ include loss of independence and aggression/ agitation. According to a panel of 11 experts recruited from urban China, patients with moderate-to-severe $\mathrm{AD}$ who are aggressive require additional support compared to those who are non-aggressive. Among dependent patients, aggression is associated with increased likelihood of placement in a hospital rather than a nursing home (70-90\% hospitalization rate vs. 5-35\%) [98]. Among independent patients, aggression is associated with an increased requirement for caregiver time (12 to 15 hours vs. 1 to 3 hours). A study conducted in the USA also showed a link between agitation and risk of institutionalization. Among patients with $\mathrm{AD}$, the risk of institutionalization was significantly higher in agitated patients compared with those who were not agitated (OR $1.20,95 \%$ CI 1.08, 1.33); the burden of institutionalization was considerable (incremental cost of $\$ 50,588$ per institutionalized patient) [99].

\section{Economic Burden of MCI due to AD}

MCI Costs Studies of individuals with MCI typically show that this condition is associated with increased medical costs [100]. A retrospective analysis of Medicare expenditures found that during the 2 years following a clinical diagnosis of MCI, direct costs were increased considerably in patients with MCI $(n=2826)$ compared with those of propensity-matched controls [100]. The cost difference was highest in the initial year following diagnosis (year 1: MCI, \$1698 per month; controls, \$724 per month; year 2: MCI, \$1191 per month; controls, $\$ 845$ per month) [100]. Similarly, a prospective study (GERAS-US) found that a cohort of patients $(n=677)$ with MCI, as evidenced by MMSE score, incurred a monthly societal cost of $\$ 2816$ or $\$ 2035$ depending on the method of imputation of informal care costs [72]. Conversely, an analysis of direct medical costs in patients with amnestic MCI (aMCI, as evidenced by CDR-SB [sum of boxes] score of 0.4 to 4.0, with higher CDR-SB scores indicative of mild [4.5 to 9.0], moderate [9.5 to 15.5], or severe $[\geq 16.0]$ dementia) estimated that such expenditures were not significantly increased over those of unaffected controls (aMCI vs. controls, $-\$ 5459,95 \%$ CI $-\$ 6186$ to $\$ 17106$ ) [89].

MCI Resource Use A US database study that compared patients with clinically diagnosed MCI $(n=5648)$ and those with $\mathrm{AD}(n=3768)$ found that during the 3 years prior to diagnosis, patients with $\mathrm{AD}$ had lower overall resource use (adjusted rate ratio, 0.94, 95\% CI 0.90 to 0.97), outpatient visits (adjusted rate ratio, 0.91, 95\% CI 0.88 to 0.95 ), and ED visits (adjusted rate ratio, $0.77,95 \%$ CI 0.69 to 0.87 ), but more than double the use of long-term care services (adjusted rate ratio, 2.35 , 95\% CI 1.92 to 2.88 ) [101]. Similarly, the abovementioned analysis of Medicare expenditures associated with a diagnosis of MCI found increased resource use, including more hospitalizations and longer stays as well as more physician visits and home health services [100].

Prolongation of MCI Stage A long-term model evaluating the economic impact of prolonging the MCI stage via a treatment that delays progression to $\mathrm{AD}$ dementia estimated that such an approach would have the potential for substantial cost savings in the EU [4]. A treatment that reduced the incidence of $\mathrm{AD}$ dementia by $10 \%$ (by delaying progression from $\mathrm{MCI}$ ) was estimated to reduce the total economic impact of $\mathrm{AD}$ by $6.5 \%$ in 2030 . Greater reductions in incidence (e.g., 20\% and 30\%) were associated with even greater reductions in the total cost burden (20\% and 34\%, respectively) [4]. A model developed in a Swedish setting found that a treatment that reduced progression from $\mathrm{MCI}$ due to $\mathrm{AD}$ to $\mathrm{AD}$ dementia by $25 \%$ would likely be cost-effective at a willingness-to-pay threshold of $\$ 70,000$ per quality-adjusted lifeyear (QALY) gained [102].

\section{DISCUSSION}

Twenty-one AD- or dementia-specific instruments for assessing health-related QoL (HRQoL) and ADL in patients with $\mathrm{AD}$ dementia were identified in the literature review. Diseasespecific instruments are preferred over general 
instruments in the context of dementia because the latter may lack the sensitivity to detect key aspects of the burden of dementia, such as caregiver burden [14-16]. Key factors associated with HRQoL in patients with AD dementia include social engagement, relationship with caregiver, religious beliefs or spirituality, mood, and ability to perform ADLs [12, 13, 20-24]. While basic ADLs (e.g., self-feeding, personal hygiene) and instrumental ADLs (e.g., reading, telephone use, and managing finances) are associated with patient- and caregiver-rated HRQoL, instrumental ADLs are more sensitive to the cognitive decline associated with $\mathrm{AD}$ dementia [48]. Of note, dementia severity has not been shown to have a major impact on patient-reported HRQoL in patients with AD, which may be due in part to a discrepancy in patient-reported and caregiver-reported HRQoL that may be attributable to patients' lack of awareness at more advanced stages of dementia $[12,13,43,44]$. Other reasons for this discrepancy include the presence of behavioral/psychiatric symptoms, patients' degree of dependence, and caregiver factors such as burden and stress, which tend to have a greater negative impact on caregiver-rated HRQoL compared with patient-rated HRQoL [30, 32, 34, 35].

Reductions in HRQoL were observed in patients with MCI due to $\mathrm{AD}$, along with increased psychiatric burden and reduced social activity [38]. Poor sleep quality and depressive symptoms have been shown to play a role in reduced HRQoL in patients with $\mathrm{MCI}$ $[39,40,42]$.

While disease-specific measures of QoL are typically preferred to generic measures in $\mathrm{AD}$ dementia, assessment of utilities have usually relied on general instruments such as the EQ5D, HUI2, and HUI3 [55]. The EQ-5D was found to be better correlated with other outcome measures compared with other general instruments and even the dementia-specific QoL-AD [56]. However, other studies, including the prospective GERAS study, have highlighted the limitations of generic measures such as the EQ$5 \mathrm{D}$ in patients with $\mathrm{AD}$ dementia [16]. In particular, EQ-5D utilities appear to have the same limitations as patient-rated HRQoL, as EQ-5D utilities are only weakly correlated with caregiver-rated HRQoL [58].

The combination of rising prevalence and increasing cost of care (including both formal and informal care) is projected to lead to an increase in total societal costs of up to tenfold from 2010 to 2050 [4-7].

$\mathrm{AD}$ is associated with a considerable economic burden to society that is inclusive of direct costs (medical and non-medical) and indirect costs (most substantially the burden of informal, unpaid caregiving, but also lost productivity and intangible costs). This societal burden is estimated to be more than $\$ 958$ billion worldwide and it is expected to increase severalfold over the next three decades, with the vast majority of increased costs (90\%) incurred in high-income countries [4-7, 62]. This estimated increase in costs is driven by the rising prevalence of $\mathrm{AD}$ dementia as the population ages and increases in per-patient costs. Key drivers of per-patient costs include dementia severity, patient dependence level, cognitive and/or functional decline, institutionalization, comorbidity burden, and behavioral symptoms (particularly agitation/aggression). The relationship between dementia severity and costs is stronger for informal care costs and direct nonmedical costs than for direct medical costs, which is consistent with the observation of progressive cognitive and functional decline as AD progresses. Similarly, AD dementia is associated with increased resource use, particularly among more severely affected patients $[66,70,79,85,88-90,95]$.

Several studies have observed substantial medical costs and/or resource use in patients with MCI, including one study that found a higher cost burden compared with controls with normal cognition [72, 100, 101]. However, recent models have shown that a treatment that could reduce the incidence of $\mathrm{AD}$ by prolonging the MCI stage was likely to reduce the expected burden of $\mathrm{AD}[4,102]$.

In the literature identified in this review, $\mathrm{AD}$ (including MCI and dementia) was most often reported as a clinical diagnosis based on the 1984 NINCDS-ADRDA criteria, the 2011 NIA-AA criteria, the DSM-IV criteria, and/or diagnostic codes. However, a 2018 NIA-AA research 
framework and a 2021 international working group on the diagnosis of $\mathrm{AD}$ have recommended clinical-biological diagnostic criteria that incorporate biomarker evidence of $\mathrm{AD}$ pathology (amyloid- and tau-positive status) in addition to clinical phenotypic evidence to support a diagnosis of MCI due to $\mathrm{AD}$ or $\mathrm{AD}$ dementia [103, 104]. Future research on the humanistic and economic burden of $\mathrm{AD}$ should be conducted in patients diagnosed with $\mathrm{AD}$ based on clinical and biomarker criteria, as was recently done in an analysis by Robinson et al. [72].

\section{CONCLUSIONS}

Our review of the literature highlights the considerable humanistic burden of $\mathrm{AD}$, as evidenced by its impact on patient and caregiverreported outcomes, as well as the increasing cost of care.

\section{ACKNOWLEDGEMENTS}

Funding. Eisai provided the funding for the literature review and the manuscript, including the journal's Rapid Service Fees.

Authorship. All named authors meet the International Committee of Medical Journal Editors (ICJME) criteria for authorship for this article, take responsibility for the integrity of the work as a whole, and have given their approval for this version to be published.

Author Contributions. All authors contributed to the conception and design of the manuscript. Quanwu Zhang and Amir Tahami provided the idea behind the article, Michael Byrnes conducted the literature review, Michael Byrnes and Leigh Ann White designed and drafted the manuscript, and Quanwu Zhang and Amir Tahami provided feedback and critical analysis of literature review methods, manuscript outlines, and manuscript text. Karin Hawkinson contributed to the development of the sections of the manuscript focused on humanistic burden.

Disclosures. Quanwu Zhang and Amir Tahami are employees of Eisai; Michael Byrnes, Leigh Ann White, and Karin Hawkinson are employees of Evidera, Inc.

Compliance with Ethics Guidelines. This article is based on previously conducted studies and does not contain any new studies with human participants or animals performed by any of the authors.

Data Availability. Data sharing is not applicable to this article as no datasets were generated or analyzed during the current study.

Open Access. This article is licensed under a Creative Commons Attribution-NonCommercial 4.0 International License, which permits any non-commercial use, sharing, adaptation, distribution and reproduction in any medium or format, as long as you give appropriate credit to the original author(s) and the source, provide a link to the Creative Commons licence, and indicate if changes were made. The images or other third party material in this article are included in the article's Creative Commons licence, unless indicated otherwise in a credit line to the material. If material is not included in the article's Creative Commons licence and your intended use is not permitted by statutory regulation or exceeds the permitted use, you will need to obtain permission directly from the copyright holder. To view a copy of this licence, visit http://creativecommons.org/licenses/bync/4.0/.

\section{REFERENCES}

1. Atri A. The Alzheimer's disease clinical spectrum: diagnosis and management. Med Clin N Am. 2019;103(2):263-93.

2. Jack CR Jr, Knopman DS, Jagust WJ, et al. Tracking pathophysiological processes in Alzheimer's disease: an updated hypothetical model of dynamic biomarkers. Lancet Neurol. 2013;12(2):207-16. 
3. Scheltens P, Blennow K, Breteler MM, et al. Alzheimer's disease. Lancet. 2016;388(10043):505-17.

4. Cimler R, Maresova P, Kuhnova J, et al. Predictions of Alzheimer's disease treatment and care costs in European countries. PLoS ONE. 2019;14(1): e0210958.

5. Clay E, Zhou J, Yi ZM, et al. Economic burden for Alzheimer's disease in China from 2010 to 2050: a modelling study. J Market Access Health Policy. 2019;7(1):1667195.

6. Jia J, Wei C, Chen S, et al. The cost of Alzheimer's disease in China and re-estimation of costs worldwide. Alzheimers Dement. 2018;14(4):483-91.

7. Zissimopoulos J, Crimmins E, St CP. The value of delaying Alzheimer's disease onset. Forum Health Econ Policy. 2014;18(1):25-39.

8. Albert MS, DeKosky ST, Dickson D, et al. The diagnosis of mild cognitive impairment due to Alzheimer's disease: recommendations from the National Institute on Aging-Alzheimer's Association workgroups on diagnostic guidelines for Alzheimer's disease. Alzheimers Dement. 2011;7(3):270-9.

9. McKhann GM, Knopman DS, Chertkow H, et al. The diagnosis of dementia due to Alzheimer's disease: recommendations from the National Institute on Aging-Alzheimer's Association workgroups on diagnostic guidelines for Alzheimer's disease. Alzheimers Dement. 2011;7(3):263-9.

10. Sperling RA, Aisen PS, Beckett LA, et al. Toward defining the preclinical stages of Alzheimer's disease: recommendations from the National Institute on Aging-Alzheimer's Association workgroups on diagnostic guidelines for Alzheimer's disease. Alzheimers Dement. 2011;7(3):280-92.

11. Dourado MC, Sousa MF, Santos RL, et al. Quality of life in mild dementia: patterns of change in self and caregiver ratings over time. Braz J Psychiatry. 2016;38(4):294-300.

12. Castro-Monteiro E, Alhayek-Ai M, Diaz-Redondo A, et al. Quality of life of institutionalized older adults by dementia severity. Int Psychogeriatr. 2016;28(1): 83-92.

13. Martyr A, Nelis SM, Quinn C, et al. Living well with dementia: a systematic review and correlational meta-analysis of factors associated with quality of life, well-being and life satisfaction in people with dementia. Psychol Med. 2018;48(13):2130-9.

14. Webster L, Groskreutz D, Grinbergs-Saull A, et al. Development of a core outcome set for disease modification trials in mild to moderate dementia: a systematic review, patient and public consultation and consensus recommendations. Health Technol Assess (Winchester, Engl). 2017;21(26):1-192.

15. Roen I, Selbaek G, Kirkevold O, et al. Resource Use and Disease Course in dementia-Nursing Home (REDIC-NH), a longitudinal cohort study; design and patient characteristics at admission to Norwegian nursing homes. BMC Health Serv Res. 2017;17(1):365.

16. Reed C, Barrett A, Lebrec J, et al. How useful is the EQ-5D in assessing the impact of caring for people with Alzheimer's disease? Health Qual Life Outcomes. 2017;15(1):16.

17. Torisson G, Stavenow L, Minthon L, et al. Reliability, validity and clinical correlates of the Quality of Life in Alzheimer's disease (QoL-AD) scale in medical inpatients. Health Qual Life Outcomes. 2016;14:90.

18. American Psychiatric Association. Diagnostic and statistical manual of mental disorders: DSM-IV. 4th ed. Washington, D.C.: American Psychiatric Association; 1994.

19. McKhann G, Drachman D, Folstein M, et al. Clinical diagnosis of Alzheimer's disease: report of the NINCDS-ADRDA Work Group under the auspices of Department of Health and Human Services Task Force on Alzheimer's Disease. Neurology. 1984;34(7):939-44.

20. Gomez-Gallego M, Gomez-Garcia J, Ato-Lozano E. The mediating role of depression in the association between disability and quality of life in Alzheimer's disease. Aging Ment Health. 2017;21(2):163-72.

21. Barbe C, Jolly D, Morrone I, et al. Factors associated with quality of life in patients with Alzheimer's disease. BMC Geriatr. 2018;18(1):159.

22. Barbe C, Morrone I, Wolak-Thierry A, et al. Impact of functional alterations on quality of life in patients with Alzheimer's disease. Aging Ment Health. 2017;21(5):571-6.

23. Beerens HC, de Boer B, Zwakhalen SM, et al. The association between aspects of daily life and quality of life of people with dementia living in long-term care facilities: a momentary assessment study. Int Psychogeriatr. 2016;28(8):1323-31.

24. Millenaar J, Hvidsten L, de Vugt ME, et al. Determinants of quality of life in young onset dementia results from a European multicenter assessment. Aging Ment Health. 2017;21(1):24-30.

25. Akpınar Söylemez B, Küçükgüçlü Ö, Akyol MA, et al. Quality of life and factors affecting it in patients with Alzheimer's disease: a cross-sectional study. Health Qual Life Outcomes. 2020;18(1):304. 
26. Dourado MCN, Santos RL, Fischer A, et al. Modeling Quality of Life in Alzheimer Disease: the impact of cognitive, functional, and mood variables in self and carers' perceptions. J Geriatr Psychiatry Neurol. 2020;34:668-74.

27. Lima S, Sevilha S, Pereira MG. Quality of life in early-stage Alzheimer's disease: the moderator role of family variables and coping strategies from the patients' perspective. Psychogeriatrics. 2020;20(5): 557-67.

28. Schumann C, Alexopoulos P, Perneczky R. Determinants of self- and carer-rated quality of life and caregiver burden in Alzheimer disease. Int J Geriatr Psychiatry. 2019;34(10):1378-85.

29. Smit D, de Lange J, Willemse B, et al. Activity involvement and quality of life of people at different stages of dementia in long term care facilities. Aging Ment Health. 2016;20(1):100-9.

30. Zucchella C, Bartolo M, Bernini S, et al. Quality of life in Alzheimer disease: a comparison of patients' and caregivers' points of view. Alzheimer Dis Assoc Disord. 2015;29(1):50-4.

31. Hongisto K, Hallikainen I, Selander T, et al. Quality of Life in relation to neuropsychiatric symptoms in Alzheimer's disease: 5-year prospective ALSOVA cohort study. Int J Geriatr Psychiatry. 2018;33(1): 47-57.

32. Orgeta V, Orrell M, Hounsome B, et al. Self and carer perspectives of quality of life in dementia using the QoL-AD. Int $\mathrm{J}$ Geriatr Psychiatry. 2015;30(1):97-104.

33. Sousa MFB, Santos RL, Simoes P, et al. Discrepancies between Alzheimer's disease patients' and caregivers' ratings about patients' quality of life: a 1-year observation study in Brazil. Alzheimer Dis Assoc Disord. 2018;32(3):240-6.

34. Huang HL, Weng LC, Tsai YH, et al. Predictors of self- and caregiver-rated quality of life for people with dementia living in the community and in nursing homes in northern Taiwan. Int Psychogeriatr. 2015;27(5):825-36.

35. Kimura NRS, Baptista MAT, Santos RL, et al. Caregivers' perspectives of quality of life of people with young- and late-onset Alzheimer disease. J Geriatr Psychiatry Neurol. 2018;31(2):76-83.

36. Sousa MF, Santos RL, Nogueira ML, et al. Awareness of disease is different for cognitive and functional aspects in mild Alzheimer's disease: a one-year observation study. J Alzheimers Dis. 2015;43(3): 905-13.
37. Stites SD, Karlawish J, Harkins K, et al. Awareness of mild cognitive impairment and mild Alzheimer's disease dementia diagnoses associated with lower self-ratings of quality of life in older adults. J Gerontol B Psychol Sci Soc Sci. 2017;72(6):974-85.

38. Anderson ND. State of the science on mild cognitive impairment (MCI). CNS Spectr. 2019;24(1):78-87.

39. Song D, Yu DS, Li PW, et al. Correlates of healthrelated quality of life among Chinese older adults with mild cognitive impairment. Clin Interv Aging. 2019;14:2205-12.

40. Stites SD, Harkins K, Rubright JD, et al. Relationships between cognitive complaints and quality of life in older adults with mild cognitive impairment, mild Alzheimer disease dementia, and normal cognition. Alzheimer Dis Assoc Disord. 2018;32(4): 276-83.

41. Roehr S, Luck T, Pabst A, et al. Subjective cognitive decline is longitudinally associated with lower health-related quality of life. Int Psychogeriatr. 2017;29(12):1939-50.

42. Leng M, Yin $H$, Zhang $P$, et al. Sleep quality and health-related quality of life in older people with subjective cognitive decline, mild cognitive impairment, and Alzheimer Disease. J Nerv Ment Dis. 2020;208(5):387-96.

43. Trigg R, Jones RW, Knapp M, et al. The relationship between changes in quality of life outcomes and progression of Alzheimer's disease: results from the dependence in $\mathrm{AD}$ in England 2 longitudinal study. Int J Geriatr Psychiatry. 2015;30(4):400-8.

44. Olazaran J, Aguera-Ortiz L, Argimon JM, et al. Costs and quality of life in community-dwelling patients with Alzheimer's disease in Spain: results from the GERAS II observational study. Int Psychogeriatr. 2017;29(12):2081-93.

45. Hongisto K, Väätäinen S, Martikainen J, et al. Selfrated and caregiver-rated quality of life in Alzheimer disease with a focus on evolving patient ability to respond to questionnaires: 5-year prospective ALSOVA cohort study. Am J Geriatr Psychiatry. 2015;23(12):1280-9.

46. Robinson RL, Rentz DM, Bruemmer $\mathrm{V}$, et al. Observation of patient and caregiver burden associated with early Alzheimer's disease in the United States: design and baseline findings of the GERASUS Cohort Study1. J Alzheimers Dis. 2019;72(1): 279-92.

47. Kahle-Wrobleski K, Andrews JS, Belger M, et al. Dependence levels as interim clinical milestones along the continuum of Alzheimer's disease: 
18-month results from the GERAS observational study. J Prev Alzheimers Dis. 2017;4(2):72-80.

48. Clemmensen FK, Hoffmann K, Siersma V, et al. The role of physical and cognitive function in performance of activities of daily living in patients with mild-to-moderate Alzheimer's disease - a cross-sectional study. BMC Geriatr. 2020;20(1):513.

49. Ascher-Svanum H, Chen YF, Hake A, et al. Cognitive and Functional Decline in Patients With Mild Alzheimer Dementia With or Without Comorbid Diabetes. Clin Ther. 2015;37(6):1195-205.

50. Doody RS, Raman R, Farlow M, et al. A phase 3 trial of semagacestat for treatment of Alzheimer's disease. N Engl J Med. 2013;369(4):341-50.

51. Giebel CM, Challis DJ, Montaldi D. A revised interview for deterioration in daily living activities in dementia reveals the relationship between social activities and well-being. Dementia (London). 2016;15(5):1068-81.

52. Sun M, Mainland BJ, Ornstein TJ, et al. The association between cognitive fluctuations and activities of daily living and quality of life among institutionalized patients with dementia. Int J Geriatr Psychiatry. 2018;33(2):e280-5.

53. Votruba KL, Persad C, Giordani B. Patient mood and instrumental activities of daily living in Alzheimer disease: relationship between patient and caregiver reports. J Geriatr Psychiatry Neurol. 2015;28(3): 203-9.

54. Roehr S, Riedel-Heller SG, Kaduszkiewicz H, et al. Is function in instrumental activities of daily living a useful feature in predicting Alzheimer's disease dementia in subjective cognitive decline? Int J Geriatr Psychiatry. 2019;34(1):193-203.

55. Li L, Nguyen KH, Comans T, et al. Utility-based instruments for people with dementia: a systematic review and meta-regression analysis. Value Health. 2018;21(4):471-81.

56. Lacey L, Bobula J, Rudell K, et al. Quality of life and utility measurement in a large clinical trial sample of patients with mild to moderate Alzheimer's disease: determinants and level of changes observed. Value Health. 2015;18(5):638-45.

57. Cheung YB, Tan HX, Wang VW, et al. Mapping the Alzheimer's Disease cooperative study-activities of daily living inventory to the health utility index mark III. Qual Life Res. 2019;28(1):131-9.

58. Michalowsky B, Xie F, Kohlmann T, et al. Acceptability and validity of the EQ-5D in patients living with dementia. Value Health. 2020;23(6):760-7.
59. Pusswald G, Moser D, Pflüger M, et al. The impact of depressive symptoms on health-related quality of life in patients with subjective cognitive decline, mild cognitive impairment, and Alzheimer's disease. Int Psychogeriatr. 2016;28(12):2045-54.

60. El-Hayek YH, Wiley RE, Khoury CP, et al. Tip of the Iceberg: assessing the Global Socioeconomic Costs of Alzheimer's Disease and Related Dementias and Strategic Implications for Stakeholders. J Alzheimers Dis. $2019 ; 70(2): 323-41$.

61. Pena-Longobardo LM, Rodriguez-Sanchez B, OlivaMoreno J, et al. How relevant are social costs in economic evaluations? The case of Alzheimer's disease. Eur J Health Econ. 2019.

62. Wimo A, Guerchet M, Ali GC, et al. The worldwide costs of dementia 2015 and comparisons with 2010. Alzheimers Dement. 2017;13(1):1-7.

63. Maresova P, Dolejs J, Kuca K. Call for a uniform strategy of collecting Alzheimer's disease costs: a review and meta-analysis. J Alzheimers Dis. 2018;63(1):227-38.

64. Darba J, Kaskens L, Lacey L. Relationship between global severity of patients with Alzheimer's disease and costs of care in Spain; results from the co-dependence study in Spain. Eur J Health Econ. 2015;16(8):895-905.

65. Nakanishi M, Igarashi A, Ueda $\mathrm{K}$, et al. Costs and resource use associated with community-dwelling patients with Alzheimer's Disease in Japan: baseline results from the prospective observational GERAS-J study. J Alzheimers Dis. 2020;74(1):127-38.

66. Reed C, Happich M, Argimon JM, et al. What drives country differences in cost of Alzheimer's Disease? An explanation from resource use in the GERAS study. J Alzheimers Dis. 2017;57(3):797-812.

67. Henderson C, Knapp M, Nelis SM, et al. Use and costs of services and unpaid care for people with mild-to-moderate dementia: Baseline results from the IDEAL cohort study. Alzheimer's Dementia (New York, N Y). 2019;5:685-96.

68. Bruno G, Mancini M, Bruti G, et al. Costs and resource use associated with Alzheimer's disease in Italy: results from an observational study. J Prev Alzheimers Dis. 2018;5(1):55-64.

69. Chiatti C, Furneri G, Rimland JM, et al. The economic impact of moderate stage Alzheimer's disease in Italy: evidence from the UP-TECH randomized trial. Int Psychogeriatr. 2015;27(9):1563-72.

70. Rapp T, Andrieu S, Chartier F, et al. Resource use and cost of Alzheimer's Disease in France: 
18-month results from the GERAS observational study. Value Health. 2018;21(3):295-303.

71. Yan X, Li F, Chen S, et al. Associated factors of total costs of Alzheimer's disease: a cluster-randomized observational study in China. J Alzheimers Dis. 2019;69(3):795-806.

72. Robinson RL, Rentz DM, Andrews JS, et al. Costs of early stage Alzheimer's disease in the United States: cross-sectional analysis of a prospective cohort study (GERAS-US)1. J Alzheimers Dis. 2020;75(2): 437-50.

73. Darba J, Kaskens L. Relationship between patient dependence and direct medical-, social-, indirect-, and informal-care costs in Spain. ClinicoEcon Outcomes Res CEOR. 2015;7:387-95.

74. Kahle-Wrobleski K, Andrews JS, Belger M, et al. Clinical and economic characteristics of milestones along the continuum of Alzheimer's disease: transforming functional scores into levels of dependence. J Prev Alzheimers Dis. 2015;2(2):115-20.

75. Michaud TL, High R, Charlton ME, et al. Dependence stage and pharmacoeconomic outcomes in patients with Alzheimer disease. Alzheimer Dis Assoc Disord. 2017;31(3):209-17.

76. Jones RW, Lebrec J, Kahle-Wrobleski K, et al. Disease Progression in Mild Dementia due to Alzheimer Disease in an 18-Month Observational Study (GERAS): the impact on costs and caregiver outcomes. Dementia Geriatr Cognitive Disord Extra. 2017;7(1):87-100.

77. Lenox-Smith A, Reed C, Lebrec J, et al. Potential cost savings to be made by slowing cognitive decline in mild Alzheimer's disease dementia using a model derived from the UK GERAS observational study. BMC Geriatr. 2018;18(1):57.

78. Belger M, Haro JM, Reed C, et al. Determinants of time to institutionalisation and related healthcare and societal costs in a community-based cohort of patients with Alzheimer's disease dementia. Eur J Health Econ. 2019;20(3):343-55.

79. Bruggenjurgen B, Andersohn F, Ezzat N, et al. Medical management, costs, and consequences of Alzheimer's disease in Germany: an analysis of health claims data. J Med Econ. 2015;18(6):466-73.

80. Chen Y, Wilson L, Kornak J, et al. The costs of dementia subtypes to California Medicare fee-forservice, 2015. Alzheimers Dement. 2019;15(7): 899-906.

81. Jones RW, Romeo R, Trigg R, et al. Dependence in Alzheimer's disease and service use costs, quality of life, and caregiver burden: the DADE study. Alzheimers Dement. 2015;11(3):280-90.

82. Bayen E, Yaffe K, Cleret de Langavant L, et al. The direct health care cost to Medicare of Down syndrome dementia as compared with Alzheimer's disease among 2015 Californian beneficiaries. Ann Phys Rehabil Med. 2020. https://doi.org/10.1016/j. rehab.2020.07.011.

83. Darbà J, Marsà A. Hospital incidence, mortality and costs of Alzheimer's disease in Spain: a retrospective multicenter study. Expert Rev Pharmacoecon Outcomes Res. 2020. https://doi.org/10.1080/ 14737167.2022.2000862.

84. Pyenson B, Sawhney TG, Steffens C, et al. The realworld medicare costs of Alzheimer disease: considerations for policy and care. J Manag Care Spec Pharm. 2019;25(7):800-9.

85. Desai U, Kirson NY, Ye W, et al. Trends in health service use and potentially avoidable hospitalizations before Alzheimer's disease diagnosis: a matched, retrospective study of US Medicare beneficiaries. Alzheimer's Dementia (Amsterdam, Netherlands). 2019;11:125-35.

86. Takechi H, Kokuryu A, Kuzuya A, et al. Increase in direct social care costs of Alzheimer's disease in Japan depending on dementia severity. Geriatr Gerontol Int. 2019;19(10):1023-9.

87. Nair R, Haynes VS, Siadaty M, et al. Retrospective assessment of patient characteristics and healthcare costs prior to a diagnosis of Alzheimer's disease in an administrative claims database. BMC Geriatr. 2018;18(1):243.

88. Lenox-Smith A, Reed C, Lebrec J, et al. Resource utilisation, costs and clinical outcomes in non-institutionalised patients with Alzheimer's disease: 18-month UK results from the GERAS observational study. BMC Geriatr. 2016;16(1):195.

89. Ton TGN, DeLeire T, May SG, et al. The financial burden and health care utilization patterns associated with amnestic mild cognitive impairment. Alzheimers Dement. 2017;13(3):217-24.

90. Takizawa C, Thompson PL, van Walsem A, et al. Epidemiological and economic burden of Alzheimer's disease: a systematic literature review of data across Europe and the United States of America. J Alzheimers Dis. 2015;43(4):1271-84.

91. Black CM, Fillit H, Xie L, et al. Economic burden, mortality, and institutionalization in patients newly diagnosed with Alzheimer's disease. J Alzheimers Dis. 2018;61(1):185-93. 
92. Black CM, Lipton RB, Thiel E, et al. Relationship between treatment initiation and healthcare costs in Alzheimer's disease. J Alzheimers Dis. 2019;68(4): 1575-85.

93. Morris S, Patel N, Baio G, et al. Monetary costs of agitation in older adults with Alzheimer's disease in the UK: prospective cohort study. BMJ Open. 2015;5(3):e007382.

94. Reed C, Belger M, Scott Andrews J, et al. Factors associated with long-term impact on informal caregivers during Alzheimer's disease dementia progression: 36-month results from GERAS. Int Psychogeriatr. 2020;32(2):267-77.

95. Khandker RK, Ritchie CW, Black CM, et al. Multinational, cross-sectional survey of healthcare resource utilization in patients with all stages of cognitive impairment, analyzed by disease severity, country, and geographical region. J Alzheimers Dis. 2020;75(4):1141-52.

96. Beydoun MA, Beydoun HA, Gamaldo AA, et al. Nationwide inpatient prevalence, predictors, and outcomes of Alzheimer's disease among Older Adults in the United States, 2002-2012. J Alzheimers Dis. 2015;48(2):361-75.

97. Keeney T, Belanger E, Jones RN, et al. High-need phenotypes in medicare beneficiaries: drivers of variation in utilization and outcomes. J Am Geriatr Soc. 2019;68:70-7.

98. Yu X, Chen S, Chen X, et al. Clinical management and associated costs for moderate and severe
Alzheimer's disease in urban China: a Delphi panel study. Translational neurodegeneration. 2015;4:15.

99. Cloutier M, Gauthier-Loiselle M, Gagnon-Sanschagrin $\mathrm{P}$, et al. Institutionalization risk and costs associated with agitation in Alzheimer's disease. Alzheimer's Dement (New York, N Y). 2019;5: 851-61.

100. Lin PJ, Zhong Y, Fillit HM, et al. Medicare expenditures of individuals with Alzheimer's disease and related dementias or mild cognitive impairment before and after diagnosis. J Am Geriatr Soc. 2016;64(8):1549-57.

101. Albrecht JS, Hanna M, Kim D, et al. Increased health care utilization in dementia subtypes before diagnosis. Alzheimer Dis Assoc Disord. 2018;32(4): 326-32.

102. Wimo A, Handels R, Winblad B, et al. Quantifying and describing the natural history and costs of Alzheimer's disease and effects of hypothetical interventions. J Alzheimers Dis. 2020;75(3): 891-902.

103. Dubois B, Villain N, Frisoni GB, et al. Clinical diagnosis of Alzheimer's disease: recommendations of the International Working Group. Lancet Neurol. 2021;20(6):484-96.

104. Jack CR Jr, Bennett DA, Blennow K, et al. NIA-AA research framework: toward a biological definition of Alzheimer's disease. Alzheimers Dement. 2018;14(4):535-62. 